Tsimpli, I.M. (2005). Peripheral Positions in early Greek. In M.Stavrou and A. Terzi (eds.) Advances in Greek Generative Syntax, Linguistics Today, pp. 179-216. Amsterdam: John Benjamins.

\title{
Peripheral Positions in Early Greek
}

\author{
Ianthi Maria Tsimpli* \\ Aristotle University of Thessaloniki
}

\begin{abstract}
This paper aims to provide a new approach to the development of clause structure in L1 acquisition on the basis of the distinction between LF-interpretable and LFuninterpretable features which is argued to have effects on learnability. The study concentrates on the acquisition of syntactic phenomena which are related to the syntax / pragmatics interface, namely focusing, dislocation and clitic-doubling in Greek. On the assumption that these syntactic phenomena involve a grammatical representation of certain functional features on 'peripheral' functional heads $(\mathrm{CP} /$ FP), the aim is to identify a developmental pattern that describes the sequence in which these structures emerge in Greek L1 acquisition. The early acquisition of the left-periphery is then juxtaposed to the relatively delayed acquisition of the inflectional domain.
\end{abstract}

\section{Introduction}


Recent work on first language acquisition has concentrated on the development of functional categories and the properties of early clause structure. The motivation has been both theoretical and empirical. Theoretically, the aim is to investigate the developmental process of parameter-setting on assumptions based on the Functional Parameterisation Hypothesis (Borer 1984, Ouhalla 1991, Chomsky 1991, 1995, a.o.). According to this hypothesis, parameters are associated with functional categories exclusively; lexical categories are part of the linguistic lexicon but not parameterised. Empirically, the aim has been to account for some 'optional' grammatical phenomena attested in early crosslinguistic data, e.g. the use of infinitival forms in root clauses and the use of null subjects. Research on the nature of the CP-domain in L1 acquisition has also been concerned with the representation of finiteness as a feature on the $\mathrm{C}$ head in verb-second languages, the nature of subject-drop as an instance of topic-drop in these languages, but, also, the structure of interrogatives in early data, i.e. the role of the wh-feature and the Q-feature in child language.

This study concentrates on the acquisition of syntactic phenomena which are related to the syntax / pragmatics interface, namely focusing, dislocation and cliticdoubling in Greek (see Marinis 2000, 2002). On the assumption that these syntactic phenomena involve a grammatical representation of certain functional features on 'peripheral' functional heads (CP / FP), the aim is to identify a developmental pattern that describes the sequence in which these structures emerge in Greek L1 acquisition. A distinction between focusing and topicalisation / dislocation is based on the assumption that focusing involves an LF-interpretable feature hosted by an individual operator (Kiss 1998, Tsimpli 1998) whereas dislocation / topicalisation do not involve Operator-movement or, in comparable terms, an LF-interpretable feature (Agouraki 1990, Tsimpli 1995) ${ }^{1}$. Instead, the topicalised / dislocated constituent in Clitic-Left 
Dislocation structures is assumed to be base-generated in a peripheral non-Operator position and the co-indexed element (clitic) in the argument position is not a variable but a pronominal.

An investigation of a different pattern in the emergence and use of these discourse-related structures will be argued to provide evidence for a developmental distinction within the set of functional features, namely between LF-interpretable and uninterpretable features. That this distinction seems to have effects on learnability has been argued for SLI children and L2 learners (Tsimpli 1997, 2001, Tsimpli and Stavrakaki 1999). On the assumption that functional features develop gradually (an assumption incompatible with Strong Continuity), a distinction based on interpretability aims to distinguish between discourse-related structures which are, however, distinct in terms of their LF-representation. Thus, structures involving an Operator in the left periphery are interpretable and, as such, they are predicted to develop earlier than structures like CLLD which do not include an Operator-variable chain.

The difference between interpretable and uninterpretable features in L1 acquisition is also examined in terms of the 'timing' in the development of structures such as focusing compared with that of Mood, Tense, Agreement and null subjects. This comparison is expected to provide a picture of the acquisition of inflectional as opposed to 'peripheral' features in Greek. It is argued that the acquisition of inflection follows acquisition of focusing and, consequently, a gradual (bottom-up) structurebuilding approach is refuted. It is, instead, proposed that the acquisition of functional structure proceeds on the basis of the interpretability distinction of features at LF, interpretable features being acquired earlier than uninterpretable ones. As a result, 
operators like negation, Q, Modality and Focus are found in child grammars from the earliest stage whereas functional features in the inflectional domain appear later ${ }^{2}$.

\section{The adult grammar}

Greek is a null subject language with rich subject-verb agreement morphology and no infinitival forms. Mood distinctions between indicative and subjunctive are morphologically marked via the presence of the subjunctive mood marker na. Imperative forms are morphologically marked on the verb's ending. Tense and Aspect distinctions are marked on the verbal form giving combinations of the [+/-past], [+/perfective] features as shown in the following examples:

a. févj-i

leave-IMP.NON-PAST.3S

'(he) leaves / is leaving'

c. éfevj-e

leave- IMP.PAST.3S

'(he) was leaving' b. $\quad *$ fíj-i (Unified Future Category)

leave-PERF.NON-PAST.3S

d. éfij-e

leave- PERF.PAST.3S

'(he) left'

(1c\&d) show that [+past] forms are marked in two ways. First, phonologically by stress-shift to the antepenultimate syllable which in the case of the disyllabic verb 'févgho' requires an augment in initial position. Second, morphologically by a change in the suffix which is thus shown to carry both agreement and tense features. Further, 
note that the non-past / perfective form in (1b) (referred to as UFC (Unified Future Category) in Tsimpli and Stavrakaki (1999), Tsimpli (2001)) is a form that may not appear on its own in a matrix or embedded clause, but requires the subjunctive or the future particle to introduce it, as shown in (2):

(2) a. na fiji

SUBJ leave-PERF.NON-PAST.3S

'(he) should go'

b. tha fiji

FUT leave- PERF.NON-PAST.3S

'(he) will go'

Nevertheless, forms such as (1b) are frequently used in early child Greek without a particle, as has been repeatedly noted in the literature (Katis 1984, Stephany 1997, Tsimpli 1992/1996, Varlokosta et al. 1998, this volume). Varlokosta et al. argue that this form is the Greek equivalent of root infinitives found in early data from languages like German, Dutch, French, etc. (Wexler 1992, 1994, Poeppel and Wexler 1993, a.o.) and suggest that there appears to be a correlation between the form in (1b) and null subjects, similar to the one found in these other languages in root infinitive contexts. Irrespective of the analysis, it appears that Greek children in early stages of linguistic development produce forms which are not appropriately marked for tense and agreement features, thus showing a developmental pattern not unlike the one found in other languages.

Turning now to word-order possibilities, adult Greek shows relative flexibility in word-order patterns. Some of the different word-orders are related to properties of 
(null) subjects and the subject position in the language (arguably, VSO (PhilippakiWarburton 1985, 1987, Tsimpli 1990, Alexiadou and Anagnostopoulou 1998)), and some to discourse-related structures, i.e. focusing and topicalisation / dislocation (Philippaki-Warburton 1985, Agouraki 1990, 1993, Alexiadou 1999, Anagnostopoulou 1994, 2001, Tsimpli 1995, Alexopoulou 1998). The latter give rise to clearer effects in the case of objects or adjuncts which appear 'displaced' from their original position. The examples in $(3 \mathrm{a}, \mathrm{b} \& \mathrm{c})$ involve CLLD (Clitic-LeftDislocation), (object) topicalisation and CID (Clitic Doubling) structures respectively. The examples in $(4 \mathrm{a}, \mathrm{b} \& \mathrm{c})$ illustrate focus-movement affecting a direct object, a predicate adjective and a manner adjunct PP, respectively.

(3) a. To vivlio, to dhiavasa.

the book it-read-1S

'The book, I read it.'

b. Afto, ti ine?

this what is-3S

'What is this?'

c. To dhiavasa to vivlio.

it-read-1S the book

'I read the book.'

(4) TIN KOPELA silavane.

the-ACC girl arrested-3P

'It was the girl that they arrested.'

b. KURASMENOS mu fenete o Janis. 


\begin{abstract}
tired-MASC.NOM me seems the-NOM Janis
'Janis seems to me to be tired.'

c. ME DHISKOLIA mu ipan oti apandise stis erotisis.

with difficulty me-told-3P that answered-3S to-the questions

'They told me that he answered the questions with difficulty.'
\end{abstract}

Following assumptions in previous studies (e.g. Agouraki 1990, Tsimpli 1990) focusing is associated with a focus-feature which triggers movement of the Focus operator to FP / CP, the implication being that structures like (4) are relevant to the LF interface and the focus-feature is LF-interpretable. On the other hand, topicalisation and CLLD structures are assumed not to involve operator-movement or an interpretable feature ${ }^{3}$ (Tsimpli 1998). Instead, they are representations relevant at a post-LF level where discourse structure is represented. With respect to cliticdoubling, it has been suggested that the $(\mathrm{cl}+)$ verb is focused in this structure (Agouraki 1993). The focused interpretation of the verb is related to its movement to the F position with the object clitic. The object DP doubled by the clitic is necessarily unfocused and in this respect its interpretation resembles that of CLLD structures ${ }^{4}$ in that the object phrase is understood as old information in both cases. Clearly, CLLD and clitic-doubling cluster together both in discourse terms but also syntactically, given that both structures involve resumptive clitics, i.e. clitics doubling morphological features specified on a co-indexed phrase (cf. Agouraki 1993, Anagnostopoulou 1994, 2001, Philippaki-Warburton \& Spyropoulos 1999, Philippaki-Warburton et al 2002 for alternative views). Nevertheless, the difference between CLLD and clitic-doubling at the syntax-discourse level is assumed to involve the verb-focusing effect associated with clitic-doubling. 
Dividing the clause structure in the lexical projection of the predicate, the inflectional functional clause structure, and the periphery (cf. Rizzi 1997), an abbreviated tree-diagram of the Greek clause is shown in (5) below:

(5)

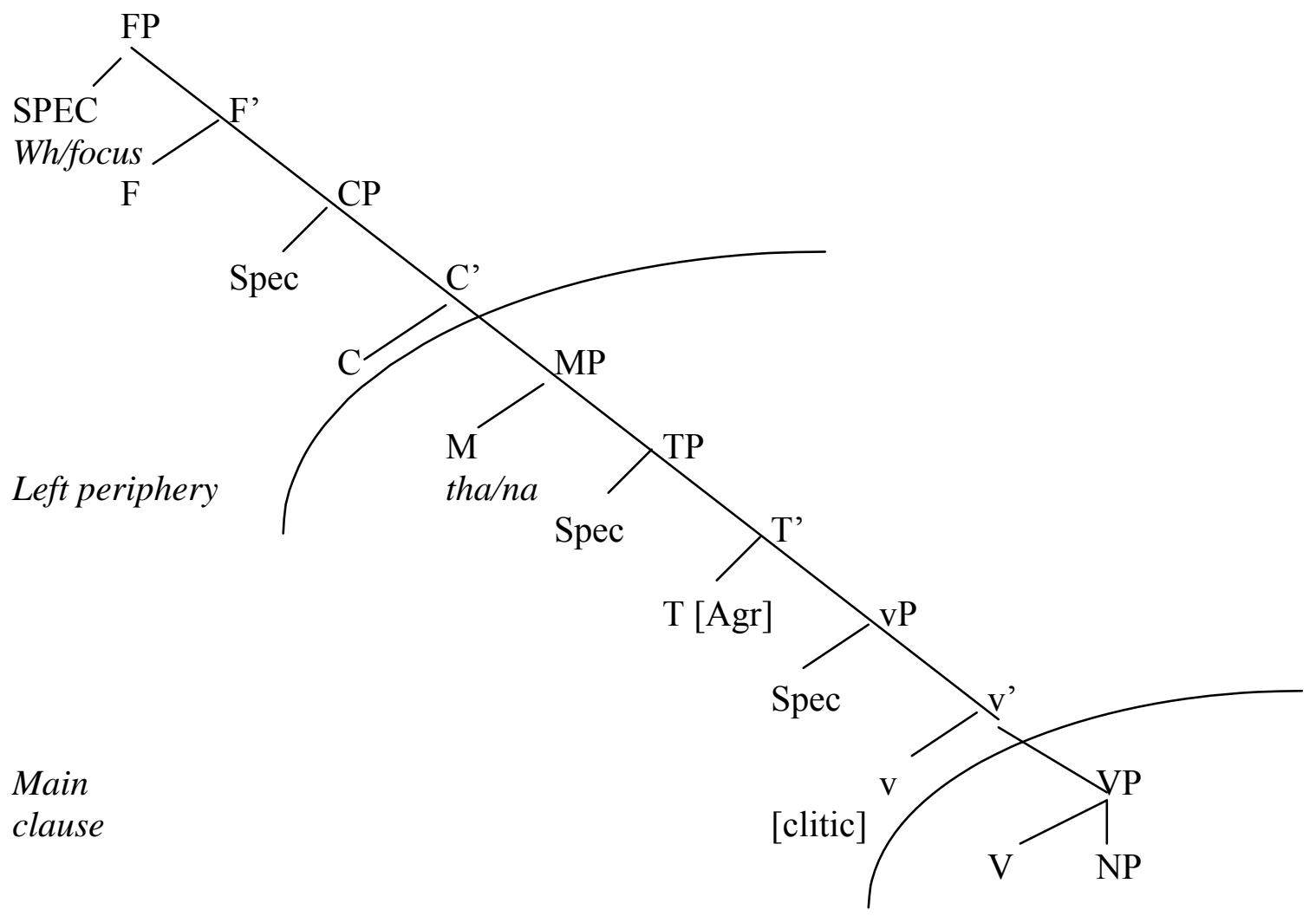

Notice that the left-periphery consists of functional heads and features which, unlike in V2 languages, are not inflectional. In the main inflectional domain of the clause, subjects and objects are associated with heads in the extended domain of the verb, i.e. the $v$ projection for clitics, case and object agreement, Tense and Mood for subjects and the modal particles ${ }^{5}$.

Given this brief outline, we may consider the predictions made for the developmental pattern of discourse-related structures such as focusing, CLLD and clitic-doubling. Before attempting to do so, some general background on alternative 
theories regarding the Initial State in first language acquisition as well as their predictions with respect to the developmental pattern followed are in order.

\section{The theory of $\mathrm{L} 1$ acquisition and predictions}

This section is only intended as a selective sketch of generative theories of first language acquisition and the assumptions they make about early clause structure. The distinction between theories of early child grammars can be drawn along two different dimensions: either as a contrast between continuity and maturation or as a contrast between theories of a 'complete' or 'incomplete' clause structure. The relevance of the present data is more obviously shown with regard to the division of theories along the second dimension, i.e. the nature of the clause structure in the early stages. As far as the maturation / continuity contrast is concerned, it is relevant to this study only insofar as the strong version of the continuity approach is concerned. Specifically, the data presented here is incompatible with strong continuity in the same way that any empirical evidence indicating selective development of functional heads is incompatible with this approach ${ }^{6}$.

With regard to the distinction between assumptions regarding 'completeness' of early clause structure, there are various suggestions. For ease of exposition, only representative examples are mentioned. Poeppel and Wexler 1993, Harris and Wexler 1996, Hyams 1996 argue for a fully-fledged clause structure with IP and CP from the earliest stage of development. Theories assuming an 'incomplete' clause structure differ, among other things, in terms of the direction in which clauses may end up incomplete at a particular stage of L1 development, i.e. bottom-up or top-down. 
Radford 1990, 1996 argues for a structure-building approach whereby lexical structure characterizes the initial state and functional categories develop gradually bottom-up ${ }^{7}$. Clahsen et al. 1996 also suggest structure-building and morphological triggers motivating the development of functional structure. The initial state includes the projection of the predicate but also an inflectional projection specified for a binary feature of finiteness. Top-down theories include the 'truncation' account for early clause structure; they differ from bottom-up theories in that functional heads are argued to be available in the initial state but child grammars may opt for a truncation option in root infinitive contexts (Rizzi 1994, Haegeman 1996). Notice that although theories of 'incomplete' early clause structure differ in many ways, some of which were mentioned above, they are similar in that they assume that functional heads are affected by 'truncation' or 'structure-building' according to the sequence in which they appear in the clause structure (Platzack 1999). Thus, in neither theory can IP be truncated or not 'built' yet, if CP is assumed to be part of the structure at the same time.

On the basis of the Greek data presented here it will be argued that the 'incomplete' clause structure theories (either structure-building ones or truncation) are problematic. In particular it will be shown that structures involving elements in peripheral positions are found in the earliest child data where tense and agreement features are not acquired as yet. The analysis is based on the following assumptions: (i) move (or merge) to scope positions (associated with LF-interpretable features, e.g. focus or Q) is part of UG, non-parameterised, therefore available from the first stage of development, (ii) parametric values of inflectional features are not interpretable at LF. One implication of these assumptions is that clause structure is acquired on the criterion of LF-interpretability of functional features. This implies that positions 
which host Operators, Focus or wh- (Q), being interpretable at LF, will be available earlier than inflectional projections. Furthermore, the left-periphery will host sentential operators like negation or modality which are also LF-interpretable ${ }^{8}$. Evidence for these features / categories is also expected to be found from the earliest stage.

First language acquisition data from very early stages of German also shows evidence for early emergence and appropriate use of focus particles (such as auch 'also') and negation (Penner et al 2000). The data from German and Swiss German suggests that even at the two-word stage of language production, German children produce focus particles and negation markers with almost no errors on 'local scrambling' of the object. Penner et al (op.cit.) claim that the constraint on scrambling definite objects is observed by the child grammar albeit not at the level of morphological production of definite determiners or case since these categories are, at the period under discussion, still underspecified. Nevertheless, it is argued that scrambled nouns are 'implicitly definite' and therefore meet the criterion for scrambling despite the absence of determiners or explicitly marked definiteness. In terms of the theory of interpretability presented here and its effects on early clause structure, the German data provides direct support not only for the early use of the focus particles - argued to be (quantificational) operators - but also for the dissociation between their emergence and the derivation they trigger, i.e. scrambling, on one hand, and the use of definite articles on the other ${ }^{9}$.

This proposal contrasts with my earlier proposal (Tsimpli 1992/1996) regarding maturation of functional categories, according to which the earliest (prefunctional) stage of L1 development consists of lexical projections only. The underlying assumption behind the distinction between lexical and functional 
categories involves their distinct cognitive status in language and cognition (see also Smith and Tsimpli 1995). Assuming that there is a further distinction within the set of functional categories based on their interpretability at LF departs from the previous lexical / functional distinction but maintains the essential characteristic of it, namely the 'double' role that interpretable features play at the LF interface on one hand, and at more 'central' cognitive processing that deals with information structure on the other.

The data presented in this study comes from Greek, a language where focusing is a grammaticalised structure relevant to the syntactic computation. Grammaticalisation of an LF-interpretable feature implies that the feature is active in the derivation (i.e. triggers Merge or Move) and that it cannot be deleted / erased at LF in that it contributes to the convergence of the representation. The difference between a grammaticalised LF-interpretable feature and a non-grammaticalised one (e.g. the contrast between Focus in Greek and Hungarian versus English) is that the former has effects on the derivation, the PF and the LF interface. Nongrammaticalised interpretable features ('weak' interpretable features) are LFinterpretable but not relevant to the derivation or the PF-interface ${ }^{10}$.

Note that topicalisation too (in the form of CLLD in Greek) is a discourserelated feature which, however, is assumed not to be LF-interpretable for reasons that have to do with its syntactic 'freedom' and status, i.e. that of a non-operator, A'element. The implication is that CLLD is a PF-phenomenon that affects the derivation (insofar as spell-out conditions on the clitic pronoun are concerned). Thus, LFinterpretability is taken to be responsible for a distinction between (i) discourserelated features, i.e. focusing and topicalisation / dislocation, and (ii) peripheral LFinterpretable features, e.g. focusing or wh- on one hand, and non-peripheral, 
uninterpretable features such as inflectional features on the verb triggering movement from the thematic domain ( $v p)$ to the inflectional domain, i.e. the main clause in (5).

Regarding predictions for a developmental pattern of the structures examined here, note first that CLLD and clitic-doubling cluster together in the adult language, not just with respect to the interpretation of the object but also syntactically, given that they both presuppose the acquisition of clitics in contexts where these are used resumptively, i.e. where clitics double morphological features specified on a coindexed phrase. Assuming that 'old information' as a discourse notion is available to the child from the earliest stage, the prediction is that when clitics are acquired the two structures should become available to the child (see Marinis 2000 for extensive discussion). Recall, however, that there is a difference between CLLD and cliticdoubling with regard to the focused interpretation of the verb in clitic-doubling but not in CLLD structures ${ }^{11}$. Therefore, if focusing is, for reasons that have to do with LF-interpretability, a structure available to the child earlier than other discourserelated structures, it is possible that, when clitics are acquired, clitic-doubling would be more frequent in early data compared to CLLD. Nevertheless, it is crucial to note that when clitics are acquired, uninterpretable parameterised features are found in the child's grammar. That is, if clitics are INFL-elements (Terzi 1999) or v-elements (Tsimpli, 1999), it follows that they are associated with functional heads including uninterpretable features. Therefore, if there is a preference or more frequent use of clitic-doubling over CLLD this is based only on discourse effects: DP-topicalisation and V-focusing in clitic-doubling as opposed to DP-topicalisation in CLLD.

Assuming that the Q-feature is also LF-interpretable, similarly with the focus feature, we expect wh-questions to involve movement to specFP, i.e. the relevant 
scope position, in the earliest stage of development. Thus, data from early interrogatives will also be included ${ }^{12}$.

Overall, the predictions with regard to the development of functional structure are the following:

(6) a. Focus and wh-structures will be target-like from the earliest stage.

b. CLLD and clitic-doubling structures presuppose the development of clitics. Clitics are realisations of uninterpretable features (Agr-O, Case). Therefore, their emergence should follow focus and whmovement.

c. Evidence for the inflectional domain (Mood, Tns, Agr) will not be found in the earliest stage and so the contrast between interpretable features of the left-periphery and Inflection will be supported developmentally.

Before presenting the data a point of caution should be made regarding comparisons between the developmental patterns of structures like focusing, CLLD and cliticdoubling. Although these structures are fully grammatical in the adult language, they are 'optional' in that their use is regulated by pragmatic / discourse-related factors. As such, the notion of obligatory context does not apply in the way that it does in the examination of L1 data regarding use of inflectional morphology, determiners etc. where conditions defining obligatory contexts are more easily specified. Therefore, acquisition of structures such as the ones investigated here refers to appropriate wordorder / interpretation pairings in the case of focusing, whereas in the case of CLLD 
and clitic-doubling morphological well-formedness in the use of clitics is also required (Marinis 2000).

\section{The data}

The data presented consists of spontaneously produced utterances from two Greekspeaking children, Alexia and Elli, recorded at regular monthly intervals ${ }^{13}$. There are four consecutive recordings for Alexia and five for Elli presented here both beginning with the earliest two-word combinations from each child. Alexia's two-word production started slightly later than Elli's $(1 ; 11$ versus $1 ; 9)$ and by the final stage presented here (Alexia, 2;2 and Elli, 2;1) the two children showed similar grammatical patterns in the use of inflection, clitics and subjects.

\subsection{Focusing, CLLD, Clitic-Doubling and Interrogatives}

Greek is a VO language with OV orders being produced as the result of object displacement to clause-initial position. In CLLD, a clitic necessarily appears prefixed to the verb whereas in focusing clitics are ungrammatical and focal stress is assigned to the moved object. In Table 1, Alexia's uses of sentences with transitive verbs are presented. Distinctions are made between uses of the unmarked VO order as well as OV, CLLD and CID (clitic-doubling) structures. Given that CLLD and CID presuppose the acquisition of clitics, the use of accusative, direct object clitics is also included in the table: 
Table 1: Alexia's word-order patterns in transitive structures

\begin{tabular}{lllllll}
\hline AGE & $\begin{array}{l}\text { TRANS. } \\
\text { STRUCT. }\end{array}$ & OV & VO & CL & CLD & CLLD \\
\hline $1 ; 11$ & 22 & 16 & 5 & 1 & 0 & 0 \\
& & $72 \%$ & $22.7 \%$ & $4 \%$ & & \\
$2 ; 0$ & 27 & 12 & 11 & 2 & 2 & 0 \\
& & $44 \%$ & $40 \%$ & $7 \%$ & $7 \%$ & \\
$2 ; 1$ & $67^{*}$ & 15 & 26 & 6 & 9 & 1 \\
& & $22 \%$ & $39 \%$ & $8 \%$ & $13 \%$ & $1 \%$ \\
$2 ; 2$ & $111^{\#}$ & 16 & 30 & 23 & 22 & 9 \\
& & $14 \%$ & $27 \%$ & $20 \%$ & $20 \%$ & $8 \%$ \\
\hline
\end{tabular}

* the remaining 10 cases include 1 object omission and 9 clausal complements.

${ }^{\#}$ the remaining 11 cases are all clausal complements.

Alexia's data shows use of focus structures with objects in preverbal position from the first recording. Clitics are used productively from $2 ; 1$ and at the same stage cliticdoubling is also used. CLLD is found in comparatively fewer contexts in the following stage only. Examples from Alexia's OV, VO, ClD and CLLD structures are given in (6) below:

(7)

a. Nelo pini atsia

(Alexia, $1 ; 11)$

water drinks alexia

'Alexia is drinking water.'

b. Seli to xataki atsia.

(Alexia, 2;0)

wants the paper-DIM alexia

'Alexia wants the paper.'

c. To anitse to fos i mama.

(Alexia, 2;1)

it opened the light the mummy

'Mummy switched on the light.'

d. Ato sa to pali i Efi.

(Alexia, 2;2) 
this will it take-3S the-NOM efi

'This, Efi will take it.'

Table 2: Elli's use of word-order patterns in transitive structures

\begin{tabular}{lllllll}
\hline AGE & $\begin{array}{l}\text { TRANS. } \\
\text { STRUCT. }\end{array}$ & OV & VO & CL & CLD & CLLD \\
\hline $1 ; 9$ & $49^{*}$ & 8 & 26 & 4 & 0 & 0 \\
& & $18 \%$ & $60 \%$ & $9 \%$ & & \\
$1 ; 10$ & $82^{*}$ & 24 & 42 & 11 & 2 & 0 \\
& & $29 \%$ & $51 \%$ & $13 \%$ & $3 \%$ & \\
$1 ; 11$ & 40 & 12 & 17 & 9 & 2 & 0 \\
& & $30 \%$ & $42 \%$ & $22 \%$ & $5 \%$ & \\
$2 ; 0$ & $78^{\#}$ & 19 & 24 & 10 & 18 & 2 \\
& & $24 \%$ & $31 \%$ & $13 \%$ & $23 \%$ & $2.5 \%$ \\
$2 ; 1$ & 101 & 7 & 53 & 25 & 9 & 3 \\
& & $6 \%$ & $52 \%$ & $25 \%$ & $9 \%$ & $3 \%$ \\
\hline
\end{tabular}

${ }^{*}$ The remaining cases are instances of object omission.

${ }^{\#}$ Of the remaining cases, 2 are object omissions and 3 clausal complements.

The remaining 4 cases are clausal complements.

In the first month of Elli's data we find a relatively large number of object omission $(22 \%)$ which is radically reduced in the second month $(4 \%)$. OV orders are found from the first stage, as in Alexia's data, but there is individual variation in the frequency in which $\mathrm{OV}$ focus structures are used. Within the set of transitive structures are included copula structures of the form 'this is John's' / 'this is dirty' which are used frequently in Elli's speech. At 1;10, the copula is missing from these structures leaving the sentence with a Noun-Noun or Noun-Adjective combination. Almost half of these structures are in the marked predicate / argument order which is also found in later stages too when the copula is appropriately used (e.g. from 1;11 onwards). Examples of Elli's sentences from various stages are provided below: 
(8) a. Tuto kopsi. (Elli, 1;9)

this cut-UFC-3S

'You should cut this.'

b. Su valis. (Elli, 1;9)

you-put-UFC-2S

'I want you to put the earrings on me.'

c. To javasume to ned. (Elli, $1 ; 11)$

it read- UFC-1P the ned

'I want us to read Ned.'

d. Thes stafili ki allo. (Elli, 2;0)

want-2S grape and more

'I want more grapes.'

e. Paputsia tis mamas to foes i elli (Elli, 2;1)

shoes the-GEN mummy it-wear- UFC-3S the-NOM elli

'Elli will wear mummy's shoes.'

f. Vomiko to vivlio. (Elli, $1 ; 10)$

dirty the book

'The book is dirty.'

g. Papaki tuto. (Elli, 1;9)

daddy's this

'This is daddy's.'

In Elli's data, clitic-doubling structures precede the use of CLLD, as is the case in Alexia's data too. 
To summarise, the data presented shows that 'marked', i.e. non-VO, patterns are found even in the earliest data. It is noteworthy that the preverbal object in all these cases is appropriately marked for heavy stress and it has a contrastive or identificational reading. Clitic-doubling seems to coincide with the development of clitics whereas CLLD lags behind in its uses compared to clitic-doubling. Thus, in developmental terms we find an initial stage where object clitics, clitic-doubling and CLLD are not used by the two children (see also Marinis 2000) but focusing is. We could then assume that an operator position, namely specFP, is available from the earliest stage in Greek child grammar. When clitics appear, the number of VO utterances with NP objects seems to decrease in favour of clitic pronouns. At this stage, focusing continues to be available both as head-movement in clitic-doubling where the cl+verb complex moves to $\mathrm{F}$ and as phrasal-movement in ordinary focus structures. Notice that from the earliest stages wh-questions also appear in the speech of both children as shown in Tables 3 and 4 below:

Table 3: Alexia's questions

\begin{tabular}{llllll}
\hline Age & 'Pu' (where) & 'Ti' (what) & Other wh- & $\begin{array}{l}\text { Copula } \\
\text { Questions }\end{array}$ & Total \\
\hline $1 ; 11$ & $3(75 \%)$ & $1(25 \%)$ & 0 & $3 / 4(75 \%)$ & 4 \\
$2 ; 0$ & $8(62 \%)$ & $5(38 \%)$ & 0 & $5 / 13(38 \%)$ & 13 \\
$2 ; 1$ & $5(42 \%)$ & $3(25 \%)$ & $4(33 \%)$ & $4 / 12(33 \%)$ & 12 \\
$2 ; 2$ & $5(20 \%)$ & $7(28 \%)$ & $13(52 \%)$ & $7 / 25(28 \%)$ & 25 \\
\hline
\end{tabular}

Table 4: Elli's questions

\begin{tabular}{llllll}
\hline Age & $\begin{array}{l}\text { 'Pu' } \\
\text { (where })\end{array}$ & 'Ti' (what) & Other wh- & $\begin{array}{l}\text { Copula } \\
\text { questions }\end{array}$ & Total \\
\hline $1 ; 9$ & $9(50 \%)$ & $6(33 \%)$ & $3(17 \%)$ & $11 / 18(61 \%)$ & 18 \\
$1 ; 10$ & $5(26 \%)$ & $9(47 \%)$ & $4(21 \%)$ & $9 / 19(47 \%)$ & 19 \\
$1 ; 11$ & $4(17 \%)$ & $14(58 \%)$ & $6(25 \%)$ & $6 / 24(25 \%)$ & 24 \\
$2 ; 0$ & $8(42 \%)$ & $9(47 \%)$ & $2(11 \%)$ & $10 / 19(52 \%)$ & 19 \\
$2 ; 1$ & $13(62 \%)$ & $7(33 \%)$ & $1(5 \%)$ & $13 / 21(62 \%)$ & 21 \\
\hline
\end{tabular}


The majority of wh-interrogatives used by the children are 'where' and 'what' interrogatives usually with a copula following the wh-word rather than another verb. All of the interrogatives produced are wh-initial. In Alexia's case 'other' whinterrogatives start being used at 2;1 and they include verb-initial yes / no questions. Examples from Alexia's and Elli's questions are presented in (9) and (10) respectively:

(9) a. Ti aponi ejo atsia?

(Alexia, 2;0)

what spread-3S here alexia

'What is Alexia spreading here?'

b. Pu pai atsia?

(Alexia, 2;0)

where go-3S alexia

'Where is Alexia going?'

c. Pu valo nelaki?

(Alexia, 2;1)

where put-1S water-DIM

'Where should I put water?'

d. Theli anitsi to fos?

(Alexia, 2;1)

want-3S open-3S the light

'Do you want me to switch on the light?'

e. Pu'ne tola to akuzaki mu? (Alexia, 2;2)

where-is now the teddy-bear my

'Where is my teddy bear now?'

f. Pos to kepazun ato?

(Alexia, 2;2)

how it cover-3P this 
'How do they cover this?'

(10) a. Pu pai Elli?

(Elli, 1;10)

where go-3S elli

'Where is Elli going?'

b. Ti kani apopos?

(Elli, $1 ; 10)$

what do-3S man

'What is the man doing?'

c. Ti kani Pitel?

(Elli, 1;11)

what do-3S peter

'What is Peter doing?'

d. Pu'ne kaseta?

(Elli, 1;11)

where-is tape

'Where is the tape?'

e. pun't'avgo? pun' avgo? (Elli, $1 ; 11)$

where-is the egg where-is egg

'Where is the egg?'

f. Ti’n aftes oles?

(Elli, 2;0)

what-are these all

'What are all these?'

g. Ti foa i Elli?

(Elli, 2;0)

what wear-3S the elli

'What is Elli wearing?'

h. Pun to hati tis ellis? (Elli, 2;1)

where-is the paper the-GEN elli-GEN 
'Where is Elli's paper?'

i. $\quad$ Ti kani to koitsaki edho? (Elli, $2 ; 1)$

what do-3S the girl-DIM here

'What is the little girl doing here?'

j. $\quad$ Pu'n tis Ellis to zaxtilizi? $\quad$ (Elli, 2;2)

where-is the-GEN elli-GEN the ring

'Where is Elli's ring?'

k. Pu pai i kukla?

where go-3S the doll

'Where is the doll going?'

It should be noted that interrogatives with the reduced copula attached to the wh-word are likely to be treated as unanalysed forms by the children especially in the first stages (Stephany, 1997). In Alexia's data, wh-questions with the copula decrease steadily in favour of other verbs whereas in Elli's case there is a decrease up to the age of 2;0. It is possible that copula questions after this age are analysed in the adult way, given the development of inflection.

From the data presented so far, it appears that peripheral positions are used from the earliest stage with focusing and wh-interrogatives preceding the other two structures. Recall that one of the predictions made earlier regarding the distinction between peripheral (focus and Q) and IP-internal positions is that the latter should appear later than the former on the basis of their LF-properties. In order to test this claim an analysis of verb forms, modal particles and subjects is required. We turn to this in the following section. 


\subsection{Tense, Agreement, Modal particles and Subjects}

In order to compare the evidence for early clause structure in Greek and given the hypothesis that the left-periphery is in place before the main inflectional domain, an analysis of morphological and syntactic properties of Inflection from the two children's production data is necessary. In the following two sections, the data from Alexia and Elli are analysed from these two perspectives. Mophologically, the emergence of the modal particles na and tha, subject-verb agreement and +/-past tense marking are presented. The aim is to compare the three functional features / categories that are assumed to be the host categories of these elements, namely Mood, Tense and Agreement. Assuming that in adult Greek, Mood carries a distinction between [+/-imperative] as well, the emergence of morphological imperatives is also examined.

Syntactically, the nature of the subject (null / overt), the position of the subject (preverbal or postverbal) and the emergence of the VSO order are discussed on the basis of the relevant data from the two children. The aim is to substantiate the suggestion that there is a correlation between morphological and syntactic acquisition when the relevant functional features / categories are in place. In the first stage of acquisition, however, this correlation is not found. Instead, morphological development shows individual variation and does not correlate with syntactic development. The underlying motivation for examining both morphological and syntactic aspects of the Inflectional domain is that 'acquisition' of functional heads or features is evidenced in both domains, i.e. the morphological and the syntactic.

\subsubsection{Alexia's use of Inflection and Subjects}


In the presentation of the data in Table 5, Alexia's use of null and overt (preverbal and postverbal) subjects, agreement and [past] tense marking, the use of the UFC (unified future category) form and modal particles (na and tha) are included. The total number of declarative sentences including transitive and intransitive verbs is included, whereas questions and imperatives are excluded. The total number of sentences examined for the analysis of the data presented in this Table is provided in 'Total' in the column 'Subjects'.

Table 5: Alexia's use of Subjects, Modal Particles, Tense and Agreement

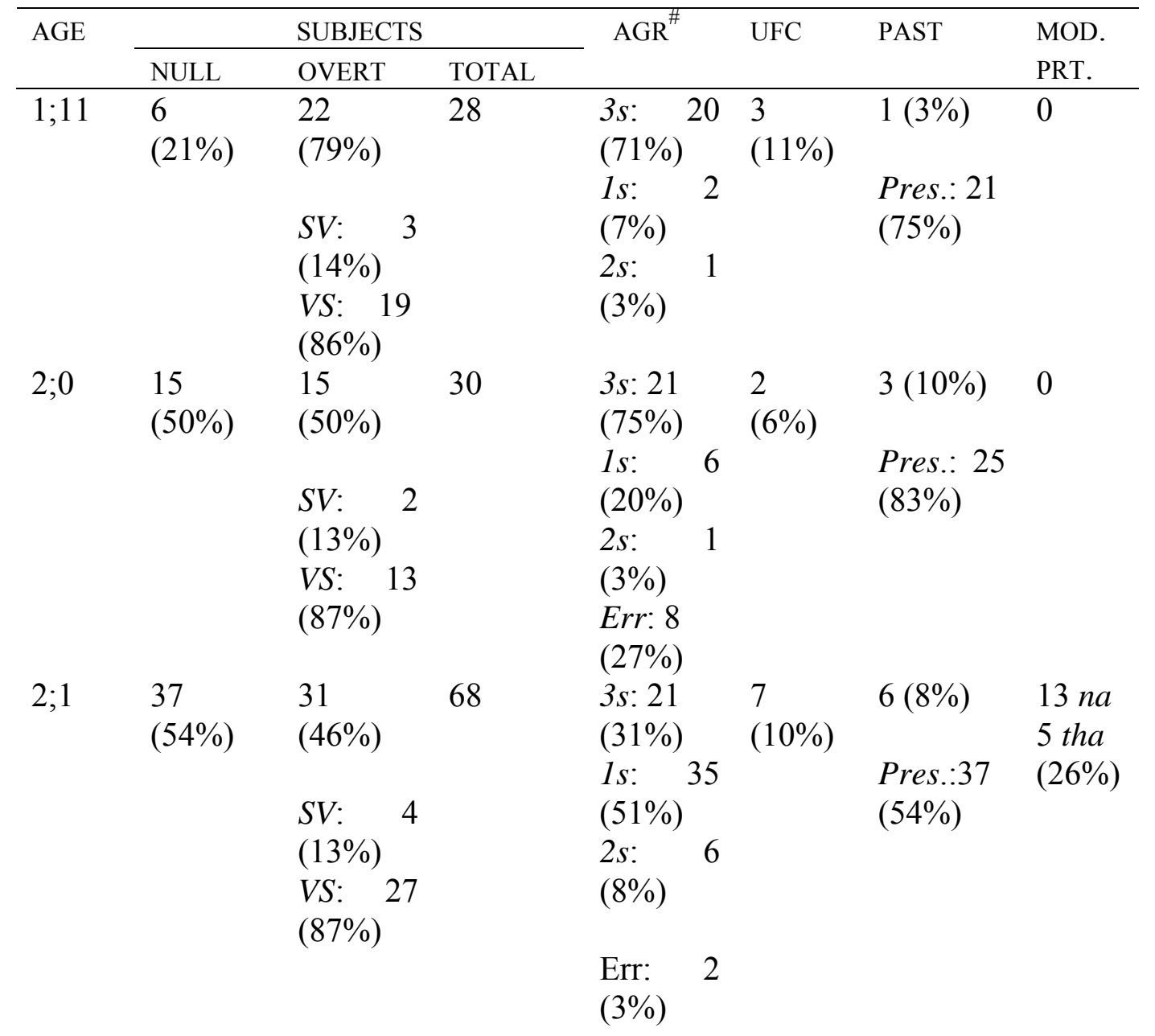




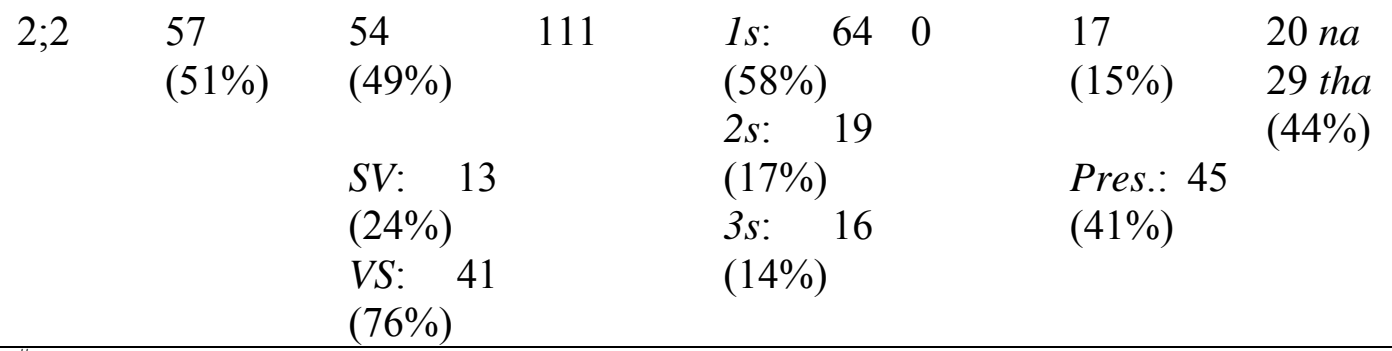

\# only the most frequent agreement endings used are presented.

With respect to the use of tense and aspect on verb forms, in the first two months Alexia uses primarily present tense forms (i.e. [-past], [-perfective]) and few instances of the UFC and past tense forms. From 2;1 the number of present forms decreases and the first occurrences of modal particles na and tha are attested. At 2;2 the UFC form is not found, present tense forms retain their frequency of use and the number of past tense forms increases. ${ }^{14}$

Subject agreement marking also shows an interesting change in the data from $2 ; 1$ where the number of $3 \mathrm{~s}$ forms is radically reduced and $1 \mathrm{~s}$ forms are used much more frequently, followed by 2 s forms. At $2 ; 2$, this pattern is strengthened. In the first two months the large majority of verb forms is in the third singular, a finding frequently noted in other studies on Greek L1 data (Katis 1984, Stephany 1997, Varlokosta et al. 1998, a.o.). Notice, however, that the overuse of this form is not related to the use of the UFC form in Alexia's data, which is, in any case, rather infrequent. Given that the majority of verbs used by Alexia in the first two months are present tense forms, if there is any correlation to be drawn here it is between third singular agreement and present tense forms. However, there is no independent reason to cluster these two features together and therefore I conclude that no grammatical link is to be sought between the choice of this agreement marker and the present tense form. 
Turning now to the use of null and overt subjects, there are two strong tendencies shown in the data. The first one is that overt subjects outnumber null subjects in the first month, whereas in the following three months null subjects are used in, roughly, half of the child's utterances. The second finding concerns the distribution of pre- and postverbal subjects. In the data from all four months, postverbal subjects constitute the overwhelming majority of overt subjects. At 2;1 and $2 ; 2$, postverbal subjects include a number of occurrences of nominative pronouns. In the data from $2 ; 1,10 / 12$ uses of the personal pronoun ego ('I') and emis ('we') appear in postverbal position. At 2;2, 29 out of a total of 38 occurrences of nominative personal pronouns appear in postverbal position. The remaining preverbal nominative pronouns usually bear focal stress as is the case with most of the preverbal subjects in Alexia's data.

Examples of the use of overt subjects are provided below:
a. Xolevi kukitsa
(Alexia, $1 ; 10)$
dance-3S doll-DIM
'The doll is dancing.'
b. Kasizi kato atsia
(Alexia, $1 ; 10$ )
sit-3S down alexia
'Alexia is sitting down.'
c. Teno penai
(Alexia, 1;11)
train pass-3S
'A train is passing.'
d. Jefilula ine apti (Alexia, 1;11)
bridge-DIM is this 
'This is a little bridge.'

e. Ejo kimate kukitsa

(Alexia, $1 ; 11$ )

here sleep-3S doll-DIM

'The doll is sleeping here.'

f. E' bolo. Mama boli

(Alexia, 2;0)

not can-1S. mummy can-3S

'I can't. Mummy can.'

g. To kepaso ego to kunelaki.

(Alexia, 2;1)

it-cover-UFC I the rabbit-DIM

'I will cover the little rabbit.'

h. Ezo mesa itane to podhalaki mu. (Alexia, 2;1)

here inside was the leg-DIM my

'My leg was in here.'

i. Dhiavazo ego. (Alexia, $2 ; 1)$

read-PRES.1S I

'I am reading.'

j. $\quad$ Penete i atsia. $\quad$ (Alexia, 2;1)

Wash-PRES.3S the alexia

'Alexia is washing herself.'

k. Ton pippo to javaso ego. (Alexia, $2 ; 1)$

the pippo it-read-UFC-1S I

'I will read Pippo.'

1. Ego tha fao gliko (Alexia, 2;1)

I will eat-1S sweet

'I will eat some sweet.' 
m. Ego tha to psakso, oxi esi (Alexia, 2;2)

I will it-look for-1S no you

'I will look for it, not you.'

n. To esploksa ego ke kateveni kato (Alexia, 2;2)

it pushed-1S I and go-3S down

'I pushed it and it's going down.'

o. Ego thartho pali edho mesa ti tileorasi (Alexia, 2;2)

I will-come-1S again here inside the television

'I will come here to the television again.'

Given that the majority of preverbal subjects is focused and the usual option for overt subjects in Alexia's and Elli's data too, as will be shown in the following section, is the postverbal position, I conclude that the unfocused preverbal subject position of the adult grammar is not available at the early stage, i.e. SpecTP.

The appearance and productive use of the first person subject pronoun at 2;1 and $2 ; 2$ can be compared with the use of the child's own name in subject position at 1;11 and 2;0. In Table 6, the percentage of use of the child's name and the first person singular nominative pronoun out of the total number of overt preverbal and postverbal subjects is presented.

Table 6: Alexia's use of her name and nominative pronoun in subject position

\begin{tabular}{lcccccc}
\hline AGE & \multicolumn{3}{c}{ PREVERBA } & \multicolumn{3}{c}{ POSTVERBAL } \\
\cline { 2 - 7 } & Name & Pronoun & $\begin{array}{c}\text { Total (N): } \\
\text { Name, Pron. } \\
\text { \& Other }\end{array}$ & Name & Pronoun & $\begin{array}{c}\text { Total (N): } \\
\text { Name, Pron. } \\
\& \text { Other }\end{array}$ \\
\hline $1 ; 11$ & $0 \%$ & $0 \%$ & 3 & $68 \%$ & $0 \%$ & 19 \\
$2 ; 0$ & $0 \%$ & $0 \%$ & 2 & $69 \%$ & $0 \%$ & 13 \\
$2 ; 1$ & $25 \%$ & $25 \%$ & 4 & $30 \%$ & $37 \%$ & 27
\end{tabular}


In the first two months no nominative pronoun is found in either subject position. On the other hand, the use of the child's name as subject is not found (except for one case) at $2 ; 2$ and at $2 ; 1$ its use is clearly reduced. Furthermore, the name occurs in preverbal position only once. When nominative pronouns are used (from $2 ; 1$ ), they are found primarily in postverbal position but do appear in preverbal position as well mostly with focused (contrastive) interpretation (see $(11 \mathrm{~m})$ ). This is also the interpretation of other preverbal subjects (e.g. (11f)).

The use of the nominative pronoun from 2;1 coincides with the increase in the use of the 1 st and 2 nd singular agreement markings on the verb. It is plausible then to suggest that the co-occurrence of the pronoun with these agreement endings is related to the acquisition of AGR-S in the child's grammar. The preference for the postverbal subject position and the focused interpretation associated with most preverbal subjects indicates that the preverbal position in Alexia's grammar is associated with the focus feature while the default order is VS. Notice, however, that in the first two months (when agreement is not as yet acquired), postverbal subjects also constitute the majority of overt subjects. This implies that the development of AGR-S does not have implications on the spell-out conditions for the subject (but see below on VSO).

Turning to the development of Mood and Tense, notice that at 2;1 the use of modal particles increases and past tense forms begin to appear. Therefore, Mood emerges at the stage that AGR-S is acquired as shown by the use of modal particles. Note that Mood is also supposed to encode [+/-imperative]; thus, the acquisition of Mood should also be evidenced by appropriate use of morphological imperatives. In Table 7 Alexia's use of negative and affirmative imperatives is presented: 
Table 7: Alexia's use of Imperatives

\begin{tabular}{cccc}
\hline AGE & AFFIRMATIVE & NEGATIVE & TOTAL \\
\hline $1 ; 11$ & 0 & 0 & 0 \\
$2 ; 0$ & 1 & 5 & 6 \\
$2 ; 1$ & 8 & 6 & 14 \\
$2 ; 2$ & 20 & 8 & 28 \\
\hline
\end{tabular}

Negative imperatives (prohibitions) are found in Alexia's data from 2;0 where there are five such negatives all of which have wrong agreement marking and two of them $(12 \mathrm{a} \& \mathrm{~b})$ have the wrong negative marker:

a. Ze kunjete, mama

(Alexia, 2;0)

not move-3S mummy

'Don't move, mummy.'

b. Ze fiji, mama

(Alexia, 2;0)

not leave-3s mummy

'Don't leave, mummy.'

c. Mi piazi atsia mam

(Alexia, 2;0)

not touch-3S alexia food

'Don't touch Alexia's food.'

d. Min pilaji ta pojalakja atsia

(Alexia, 2;0)

not touch-3S the legs-DIM alexia

'Don't touch Alexia's legs.'

e. Min pilaji atsia, baba

(Alexia, 2;0)

not touch-3S alexia daddy

'Don't touch Alexia, daddy.' 
In adult language, negative imperatives are morphologically subjunctive in that the negative marker used is $m i$, i.e. the one used in negative subjunctive clauses, and the form of the verb follows the agreement paradigm of indicatives and subjunctives. Thus, it is only affirmative imperatives that show a distinct agreement paradigm (Rivero and Terzi 1995, Philippaki-Warburton 1998). Notice, however, that affirmative matrix subjunctives can be interpreted as having imperative force. Thus, the deontic interpretation in matrix clauses can be morphologically conveyed either by using a subjunctive introduced with the marker $n a$ or by using the distinct imperative form. In Alexia's and Elli's data, affirmative sentences with imperative force are found from the earliest stage. Their morphological marking though shows individual variation: Elli primarily uses the precursor of the subjunctive form (see following section) and later the subjunctive particle itself to convey imperative force. On the other hand, Alexia uses morphological imperatives from 2;1 and all of them show correct agreement marking. The use of affirmative imperatives in Alexia's data coincides with the acquisition of agreement marking in other verb forms. It thus seems that acquisition of this category is evidenced simultaneously in distinct Mood forms too in Alexia's data. Tense distinctions are also found at this stage suggesting that Tense is acquired along with Mood and AGR-S in the course of development.

\subsubsection{Elli's use of Subjects and Inflection}

Table 8 presents Elli's use of null and overt (preverbal and postverbal) subjects, agreement and [past] tense marking, the use of the UFC form and modal particles (na and tha). The total number of sentences examined is presented under 'Total' in the column 'Subjects': 
Table 8: Elli's use of Subjects, Modal Particles, Tense and Agreement

\begin{tabular}{|c|c|c|c|c|c|c|c|}
\hline \multirow[t]{2}{*}{ AGE } & \multicolumn{3}{|c|}{ SUBJECTS } & \multirow[t]{2}{*}{$\mathrm{AGR}^{\#}$} & \multirow[t]{2}{*}{ UFC } & \multirow[t]{2}{*}{ PAST } & \multirow{2}{*}{$\begin{array}{l}\text { MOD. } \\
\text { PRT. }\end{array}$} \\
\hline & NULL & OVERT & TOTAL & & & & \\
\hline $1 ; 9$ & $\begin{array}{l}43 \\
(77 \%)\end{array}$ & $\begin{array}{l}13 \\
(23 \%) \\
S V: \quad 2 \\
(15 \%) \\
V S: \quad 11 \\
(84 \%)\end{array}$ & 56 & $\begin{array}{l}\text { 3s: } 25(46 \%) \\
\text { 1p: } 11(20 \%) \\
\text { 1s: } 10(19 \%) \\
\text { 2s: } 9(17 \%) \\
\text { Err: } 22(41 \%)\end{array}$ & $\begin{array}{l}24 \\
(43 \%)\end{array}$ & $\begin{array}{l}4(7 \%) \\
\text { Pres.: } 18 \\
(32 \%)\end{array}$ & $\begin{array}{l}4 \text { a } \\
6 \text { na } \\
(18 \%)\end{array}$ \\
\hline $1 ; 10$ & $\begin{array}{l}42 \\
(55 \%)\end{array}$ & $\begin{array}{l}34 \\
(45 \%) \\
S V: \quad 7 \\
(21 \%) \\
V S: \quad 27 \\
(36 \%)\end{array}$ & 76 & 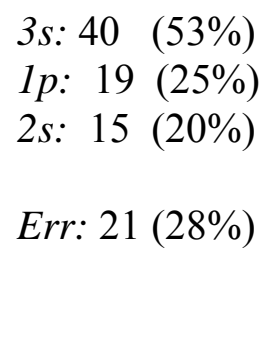 & $\begin{array}{l}23 \\
(30 \%)\end{array}$ & $\begin{array}{l}14 \\
\text { Pres.: } 28 \\
(37 \%)\end{array}$ & $\begin{array}{l}3 \text { a } \\
6 \text { na } \\
2 \text { tha }\end{array}$ \\
\hline $1 ; 11$ & $26(58 \%)$ & $\begin{array}{l}19 \\
(42 \%) \\
S V: \quad 6 \\
(32 \%) \\
V S: 13 \\
(68 \%)\end{array}$ & 45 & $\begin{array}{l}\text { 3s: } 28(62 \%) \\
2 s: 5(11 \%) \\
\text { 1s: } 6(13 \%) \\
\text { Err: } 12(27 \%)\end{array}$ & $\begin{array}{l}5 \\
(11 \%)\end{array}$ & $\begin{array}{l}7(16 \%) \\
\text { Pres.: } 22 \\
(49 \%)\end{array}$ & $\begin{array}{l}2 \text { a } \\
9 \text { na } \\
(24 \%)\end{array}$ \\
\hline $2 ; 0$ & $36(40 \%)$ & $\begin{array}{l}\begin{array}{l}55 \\
(60 \%)\end{array} \\
S V: \quad 16 \\
(29 \%) \\
V S: \quad 39 \\
(43 \%)\end{array}$ & 91 & $\begin{array}{l}\text { 3s: } 58(64 \%) \\
\text { 1p: } 15(16 \%) \\
2 s: 12(13 \%) \\
\text { Err: } 13(14 \%)\end{array}$ & $\begin{array}{l}2 \\
(2 \%)\end{array}$ & $\begin{array}{l}18 \\
(20 \%) \\
\text { Pres }^{*}: 29 \\
(32 \%)\end{array}$ & $\begin{array}{l}37 \text { na } \\
4 \text { tha } \\
(45 \%)\end{array}$ \\
\hline $2 ; 1$ & $\begin{array}{l}53 \\
(41 \%)\end{array}$ & $\begin{array}{l}76 \\
(59 \%) \\
S V: \quad 28 \\
(37 \%) \\
V S: \quad 48 \\
63 \%\end{array}$ & 129 & $\begin{array}{l}\text { 3s: } 91(71 \%) \\
\text { 1p: } 24(18 \%) \\
\text { 1s: } 6(4 \%)\end{array}$ & $\begin{array}{l}2 \\
(2 \%)\end{array}$ & $\begin{array}{l}29 \\
(22 \%) \\
\text { Pres.: } 42 \\
(33 \%)\end{array}$ & $\begin{array}{l}47 \text { na } \\
9 \text { tha } \\
(43 \%)\end{array}$ \\
\hline
\end{tabular}

"there is one instance of present perfect.

${ }^{\#}$ the most frequent agreement endings used are presented 
With regard to overt subjects, Elli, like Alexia, uses postverbal subjects considerably more frequently than preverbal ones. The rise in the percentage of preverbal subjects is due to the use of this position to mark focused subjects too. The sentences in $(13 b \& c)$ are responses to subject 'who' questions whereas (13a) is a request with a focused preverbal subject ${ }^{15}$ :
(13) a. I Elli na to plini
$($ Elli, $1 ; 11)$
the-NOM elli SUBJ it wash-3S
'Elli (wants to) wash it.'
b. I Loa eksipnise. (Elli, $1 ; 11)$
the laura woke up
'Laura woke up.'
c. I Elli toi.
$($ Elli, $1 ; 11)$
the-NOM elli is.eating
'Elli is eating.'

Unlike Alexia, Elli uses null subjects frequently from the first month. The occurrence of null subjects does not seem to correlate with the UFC form, or a specific agreement category or the combination of the UFC and 3s agreement (cf. Varlokosta et al. 1998, Varlokosta, this volume). Specifically, there are only 5 instances of the $3 \mathrm{~s}$ [-past, +perfective] form (the 'non-finite' form in Varlokosta et al.'s 1998 analysis) of which 3 appear with a null subject and 2 with an overt subject. As far as the use of agreement forms other than the third singular is concerned, a number of them is used from the first month in Elli's data, contrary to what was found in Alexia's data where the use of non-3s forms increased at $2 ; 1$ and at the same time very few agreement 
errors were produced. In Elli's case, agreement errors are found in the first three months, decrease at 2;0 and disappear at 2;1. Overall, then, acquisition of agreement in Elli's data coincides with the decrease in the number of agreement errors and does not correlate with the use of null subjects.

Table 9 below shows the distribution of agreement errors in relation to null / overt subjects and the agreement morphology produced in each case (the total number of null and overt subjects and the total number of use of third singular vs other agreement markings is also shown in Table 8 above):

Table 9: Agreement errors in Elli's data

\begin{tabular}{lcccc}
\hline \multirow{2}{*}{ AGE } & \multicolumn{2}{c}{ SUBJECTS } & \multicolumn{2}{c}{ MORPHOLOGY } \\
\cline { 2 - 5 } & NULL & OVERT & $3 \mathrm{~s}$ & OTHER \\
\cline { 2 - 5 } $1 ; 9$ & $19 / 43(44 \%)$ & $3 / 13(23 \%)$ & $9 / 25(36 \%)$ & $13 / 31(42 \%)$ \\
$1 ; 10$ & $16 / 42(38 \%)$ & $5 / 34(15 \%)$ & $6 / 40(15 \%)$ & $15 / 36(42 \%)$ \\
$1 ; 11$ & $10 / 26(38 \%)$ & $2 / 19(11 \%)$ & $2 / 28(7 \%)$ & $10 / 17(59 \%)$ \\
$2 ; 0$ & $10 / 36(28 \%)$ & $3 / 55(5 \%)$ & $1 / 58(2 \%)$ & $12 / 33(36 \%)$ \\
\hline
\end{tabular}

Some examples including agreement errors are presented in (14) below:

(14) a. Zoso katali (= na mu dhosis to kutali) (Elli, 1;9)

give-PERF-1S spoon (SUBJ me-give-2S the spoon)

'Give me the spoon.'

b. Fei kalo (= tha fero kjalo) (Elli, $1 ; 9)$

bring-3S more (will bring-1S more)

'I will bring more.'

c. miizi katses

(Elli, 1;9)

smell-3S socks

'The socks smell.' 

d. selis potokali (= thelo portokali) $\quad($ Elli, 1;10)
want-2S orange
'I want an orange.'
e. $\quad$ Vali to loloi $\mathrm{mu}$
$($ Elli, $1 ; 10)$
put-PERF-3S the watch my
'I want to put on my watch.'
f. $\quad$ a kanum palilato i Elli
$a$ do-1P bicycle the elli
'Elli wants to ride the bicycle.'
g. Tha to plino i Elli
(Elli, 1;11)
will it wash-1S the elli
'Elli will wash it.'

On the basis of the data in Table 9, it is reasonable to conclude that Elli's use of 'other' forms from the first month is partly responsible for the larger number of errors produced compared to the ones found in Alexia's data. This raises interesting questions as far as the notion of 'default' for the third singular form is concerned (Katis 1984, Stephany 1997, Tsimpli 1992/1996). In both Alexia's and Elli's data the frequency of this form is indeed greater than that of any of the other members of the agreement paradigm. On the other hand, there is individual variation as to whether this form is so frequent that it is almost exclusively used in early data (e.g. Alexia at 1;11) or whether other forms are also used (Elli, during all months). Given this difference, it is more plausible to assume that the third singular form is a default form at the morphophonological level only and not at the level of abstract morphological specification. If it were the case that the third singular is 'default' at some deeper 
level we would expect exclusive use of this form at the stage in which AGR-S is not as yet acquired by the child, contrary to fact. Furthermore, the fact that no correlation seems to be found between the use of the third singular form and null subjects, or the use of the $3 \mathrm{~s}$, -past, +perfective and null subjects supports the idea that this form is unmarked only at some surface morphological level and not otherwise (e.g. in terms of a [+/-finite] distinction (cf. Hoekstra and Hyams 1998, Varlokosta et al. 1998, Varlokosta, this volume).

As far as the development of modal particles in Elli's data is concerned, the UFC form is frequently used up to the age of $2 ; 0$; during the first three months its use is related to the use of an undifferentiated phonological place-holder a (Stephany 1997) instead of the modal particles tha and na. In other words, during this period the child uses the UFC form with or without the phonological place-holder introducing it. By $2 ; 0$, there are no uses of this place-holder and modal particles are used instead (the majority are occurrences of the subjunctive marker na). At the same time, the UFC form disappears. Tense distinctions are also found by the age of $2 ; 0$ and at that time there seems to be equal distribution between modal particles and past / present uses.

Recall that acquisition of agreement was argued to be related to the development of Mood in Alexia's data, as this is shown by the use of morphological (affirmative) imperatives as well as indicatives and subjunctives. In Elli's case, however, (affirmative) utterances with imperative force are mostly subjunctive in form, i.e. they are matrix clauses introduced by na. Notice that matrix na-clauses are not unambiguously interpreted as imperatives (see Rouchota 1994) and this is primarily the difference between them and morphologically-marked imperatives which only have an imperative reading. Nevertheless, the deontic (imperative) 
reading is a common interpretation associated with matrix subjunctives and it is found in many of the na-uses in Elli's data from 2;0 onwards.

An important point with regard to the development of modal particles is related to the 'continuity' found in the interpretation of the UFC form (with or without the place-holder introducing it) and the later verbal forms introduced by na and tha. Specifically, as noted in earlier studies (Katis 1984, Stephany 1997, Tsimpli 1992/96) these forms express boulemaic or deontic modality. The use of the future marker tha is, in some cases, associated with a modal and a (future) tense intepretation in that the child's utterance can be interpreted as her wish for something to happen rather than simply a statement about the future. In this respect, the perfective marking on the verbal form does not denote completion of an event or 'pastness' but can also denote a modal (and, therefore, necessarily future) interpretation (see Hoekstra and Hyams 1998, Hyams 2001, 2002).

Recall that tense and modal particles appear simultaneously in both children's data, i.e. (at 2;2 in Alexia's data and at 2;0 in Elli's). Assuming that Mood and Tense are functional projections that belong to the main clause (rather than the periphery) as shown in the structure in (5), and that they develop at the stages in which evidence for the use of tense distinctions and modal particles is found, how can the continuity in the expression of modal readings be explained?

Possible answers to this question are the following: (i) a strong continuity approach suggesting that Mood and Tense are represented throughout but initially they lack any morphological specification for reasons that have to do with the child's gradual development of overt morphology, (ii) Tense and Mood are not available from the beginning as independent functional heads; however, the modal reading is 
structurally represented in the periphery of the clause as a modal operator in a scope position.

The first possibility is, as it stands, incomplete. In both children's data the development of subject agreement, Mood and Tense coincide. If overt morphology develops gradually there is no reason why members of different morphological paradigms should appear at the same time. Moreover, if we assume that a null modal occupies the Mood or Tense position before overt morphology is developed (cf. Hyams 1994), we should also expect the functional heads of Mood and Tense to be syntactically available for movement to the specifier of these projections or to the head position. In the adult language, the assumption is that verb-movement always takes place in Greek (Alexiadou and Anagnostopoulou 1998, a.o.). Specifically, in the absence of infinitives, all Greek clauses should instantiate verb-raising to inflectional heads. Thus, if early Greek has the relevant inflectional heads available, according to a strong continuity perspective, we should expect verb-movement to take place. Relevant evidence should come from word-order patterns, the clearest data being declaratives in the VSO order.

\subsection{Word-order}

Assuming that $\mathrm{F}$ (the head of the Focus Phrase) is available from the earliest stage, OV structures will involve movement of the object to specFP and of the verb to $\mathrm{F}$ as is the case in the adult grammar $^{16}$ (see (5)). Furthermore, both preverbal and postverbal subjects can be represented in a structure containing the verbal and the focus projections given that preverbal subjects may appear in specFP when focused and in specVP otherwise ${ }^{17}$. Postverbal subjects, on the other hand, require different 
analyses depending on whether the structure is OVS or VOS. In the first case, the object and the verb occupy peripheral positions (in FP) and the subject remains in VP. In VOS structures, however, the subject cannot be in specVP unless the whole VP predicate is focused (cf. Sifaki 2001). Note that postverbal subjects are never prosodically stressed in the children's data; instead, they are associated with a lowfall intonation and as such they are interpreted as 'old information'. This interpretation of postverbal subjects is clearly compatible with Alexia's data where in most utterances the subject refers to the child herself through the use of her own name or of the first person singular pronoun (see Table 6). We could then suggest that postverbal subjects in VOS orders can be either in specVP if the whole VP predicate is focused or could be adjoined to a right-dislocated position and associated with a PRO subject in specVP (cf. Tsimpli 1992/96). Whatever the analysis, VOS structures do not provide evidence for the presence of the Mood and Tense projections in the clause structure.

The only, remaining, word-order pattern that necessarily presupposes movement of the verb to an inflectional head leaving the subject and the object in lower positions is VSO (cf. Philippaki-Warburton 1987, Tsimpli 1990, Alexiadou and Anagnostopoulou 1998).

Tables 10 and 11 below show the different word-order patterns used by each child during the whole period discussed here. Note that only transitive verbs with overt subjects and non-clitic objects are included ${ }^{18}$.

Table 10: Alexia's use of alternative word-order patterns

\begin{tabular}{ccccc}
\hline AGE & SVO & VSO & OVS & VOS \\
\hline $1 ; 11$ & 1 & 0 & 13 & 3 \\
$2 ; 0$ & 1 & 0 & 7 & 4
\end{tabular}




\begin{tabular}{lllcl}
\hline $2 ; 1$ & 1 & 2 & 9 & 5 \\
$2 ; 2$ & 9 & 5 & 10 & 8 \\
\hline
\end{tabular}

The VSO examples found in Alexia's data at 2;1 and 2;2 are presented in (15)-(16) below:

(15) a. je’ ponai atsia to xelaki tis

(Alexia, 2;1)

not hurts alexia the hand her

'Alexia's hand is not hurt.'

b. E'vali atsia ata. (Alexia, 2;1)

not put-3S alexia these

'Alexia (doesn't want) to put these on.'

(16) a. Tola tha kano ego nani. (Alexia, 2;2)

now will do-1S I sleep

'I will go to sleep now.'

b. Thelo ego sokolata. (Alexia, 2;2)

want-1S I chocolate

'I want chocolate.'

c. Thelo ego avgo.

(Alexia, 2;2)

want-1S I egg

'I want an egg.'

d. Ze sa kano ego banio.

(Alexia, 2;2)

not will do-1S I bath

'I won't have a bath.'

e. (Pijene) na gagalisis esi to baba ke ego ti mama (Alexia, 2;2) 
(go) SUBJ tickle-2S you the daddy and I the mummy

'Go and tickle daddy and I will tickle mummy.'

Table 11: Elli's use of word-order patterns

\begin{tabular}{ccccc}
\hline AGE & SVO & VSO & OVS & VOS \\
\hline $1 ; 9$ & 1 & 0 & 1 & 1 \\
$1 ; 10$ & 4 & 0 & 4 & 10 \\
$1 ; 11$ & 2 & 0 & 3 & 2 \\
$2 ; 0$ & 8 & 1 & 6 & 16 \\
$2 ; 1$ & 13 & 8 & 2 & 17 \\
\hline
\end{tabular}

The VSO examples found in Elli's data are presented in (17)-(18) below:

$$
\text { Na vosisi ti Elli ti Vangelia }
$$

SUBJ help-3S the elli the vangelia

'Elli should help Evangelia OR Evangelia should help Elli.'

As shown by the English translation, the example in (17) is not clearly a VSO one given that the determiners introducing the two arguments are identical and both in the accusative.

(18) a. Seli i Elli psomi. (Elli, 2;1)

want-3S the-NOM eli bread

'Elli wants bread.'

b. Na vali i Elli vutio. (2)

(Elli, 2;1)

SUBJ put-3S the-NOM eli butter

'Elli (wants to) put butter.'

c. Tomakse i Elli ti Vangelia. (Elli, 2;1) 
frightened-3S the-NOM eli the-ACC vangelia

'Elli frightened Evangelia.'

d. $\quad$ Na vali i Anna ti zaketa tis. (Elli, 2;1)

SUBJ put-3S the-NOM anna the-ACC jacket hers

'Anna should put on her jacket.'

e. Zen boi i Zafni na tis sikosi. (Elli, 2;1)

not can-3S the-NOM Dafni SUBJ them-lift-3S

'Dafni cannot lift them.'

f. $\quad$ Extipisen i Elli to xeaki. (Elli, $2 ; 1)$

hurt-3S the-NOM elli the-ACC hand

'Elli hurt her hand.'

g. $\quad$ Pezi to kunelaki tambulo. (Elli, 2;1)

play-3S the rabbit-DIM drum

'The little rabbit is playing the drum.'

What is clear from tables 10 and 11 is that in both children's data the VSO order is attested only after inflection is acquired ${ }^{19}$. Assuming, following recent assumptions (e.g. Chomsky 1995) that agreement is specified on T, verb-movement to this position becomes available when the features in question are acquired. In Elli's VSO data, examples (18b\&d) involve sentences introduced with the mood marker na. In these cases it can be argued that the verb moves and head-adjoins to Mood (cf. Terzi 1992, 1997, Roussou 1999) given that subjects and objects cannot appear between this marker and the verb (but object clitics can). Finally, negative indicatives as in $(13 \mathrm{a} \& b)$ also require verb-raising because negation is high in the clause structure and, like the subjunctive marker, it is part of the verbal complex (Tsimpli 1990, Drachman 
and Klidi 1992, Philippaki-Warburton 1994, a.o.). Overall then, the possibility that Tense and Mood are available from the earliest stage of development is untenable on the grounds that modal particles, tense and agreement distinctions are not acquired yet and the VSO order is not attested.

\subsection{Modality}

Assuming that the Mood projection is unavailable in the earliest stage, the question of how the modal interpretation is derived is still open. The second possibility mentioned in Section 3.2.2. above with respect to the modal interpretation associated with child data is that a modal operator encoding boulemaic or deontic modality can be present in a clause-peripheral position ${ }^{20}$. This assumption is consistent with a scope position of the operator in the left-periphery. A modal operator in the $\mathrm{CP}$ domain is also compatible with the alternative modal readings, e.g. the boulemaic and the deontic found in child grammars prior to the acquisition of inflection. Dissociating modality from the development of the Mood and Tense categories is a desirable result given that modal readings in early grammars are conveyed in contexts which the adult grammar distinguishes on the basis of grammaticalised Mood and Tense distinctions (Stephany 1986). For example, the UFC form, which is ungrammatical as a bare form in adult language (see section 1 above), can denote intention, wish and deontic readings in child grammar. In the adult language these readings are distinguished by the use of the future marker tha, the use of main modal verbs selecting subjunctive complement clauses and the use of morphologically marked imperatives. Subjunctive clauses have different interpretations depending on whether they are matrix or embedded. In matrix contexts they necessarily have a modal reading whose nature is 
also determined by the agreement, tense and aspectual properties of the verb form. Consider the examples below:

a. $\quad$ Na fijis!

SUBJ leave-PERF-2S

'You should go!'

b. Na éfevgha!

SUBJ leave-PAST-PERF-1S

'I wish I left.'

The strongly preferred reading of (19a) is deontic (it can also denote permission) whereas that of $(19 b)$ is optative. These readings are related to the agreement markings (2nd vs 1st singular), to the tense distinction (non-past vs past) and to the aspect marking (perfective vs imperfective) respectively. In the absence of these distinctions in early Greek, the modal interpretation is compatible with the context and is largely underspecified by the form used. In other words, although the UFC form usually encodes modality in child grammar, its morphological make-up does not grammaticalise modality in the adult grammar since it can appear as part of an embedded subjunctive (with no modal reading), as part of a verb marked for future tense (again with no modal interpretation) or as part of the present perfect form (with no modal reading either).

Furthermore, the present tense form can also convey a modal interpretation since the only difference it has from the UFC is aspectual. In other words, the contrast between the UFC and the present form is in the description of the aspectual features of each, the former being perfective and the latter imperfective. Both forms can be 
introduced by the modal particles na and tha and both forms can have modal readings associated with the use of these modal particles. Thus, the use of [-past, -perfective] forms in the earliest stages of child Greek referred to as 'present' is also compatible with a modal, future interpretation in the absence of modal particles. The implication is then that modality in early data is encoded not as a particular morphological form but as an independent feature which only needs to be compatible with the morphological specification of the verb form at the relevant stage.

In the examples below, some uses of 'present' forms with a potentially modal interpretation are presented:

a. Kubela pame

(Alexia, 2;0)

swing go-1P

'We are going to the swing. / Let's go to the swing.'

b. $\quad$ E’ kani nani Atsia

(Alexia, 2;0)

not does sleep alexia

'Alexia is not asleep. /Alexia does not want to sleep.'

c. Xolio pai Atsia.

(Alexia, 2;0)

school go-3S alexia

'Alexia is going to school. / Alexia wants to go to school.'

The two readings, a modal and a non-modal, are presented in the English translation of each form. However, in the context that the forms were produced the interpretation was modal rather than 'present' tense. The ambiguity is stronger since the verb 'pao $(=g o)$ ' and the verb ' $\operatorname{kano}(=d o)$ ' in Greek is the same in the perfective and the imperfective form. Furthermore, the modal interpretation of early negatives (e.g. 
(20b)) has been observed in child data crosslinguistically (cf. Hoekstra and Jordens 1994, Tsimpli 1992/96). Thus, modality is encoded in early grammars albeit not in the adult way where, in Greek for example, it is derived from the co-occurrence of modal particles and / or verbal inflections. It is then concluded that the 'continuity' in the modal interpretations found in child grammars involves the presence of a null modal operator in a scope position in the periphery of the clause in early and later stages (and adult grammar too). The development of inflection restricts the choices between modal interpretations but not in an unambiguous way since modality is not grammaticalised in a single verbal or other morpheme in adult Greek. In other words, on the assumption that a close relation but not identity between the categories of Mood and Modality (Palmer 2001), modality is a universal, LF-interpretable feature independent from the possible grammaticalisation of mood in different languages. The representation of modality is thus predicted to be available to all early grammars, as a modal operator in a peripheral position, regardless of the Mood properties of the adult clause.

Given that the subjunctive marker na encodes mood rather than modality, its function is associated with different contexts in some of which (primarily matrix clauses) the modal interpretation is more salient. When Mood and Tense develop, modal readings become more clearly identifiable in child language, similarly with the adult language. Overall then, the suggestion that a modal operator is structurally represented independently of Mood, Tense and Agreement can account for the modal interpretations associated with child and adult Greek. Its presence from the earliest stages of development is consistent with the claim that LF-interpretable features are available throughout, both as (abstract) morphological features and structurally in the relevant positions. Assuming that the modal operator, qua operator, is represented in 
the clause's periphery, child utterances conveying modality are structurally represented as FP / CP clauses throughout.

\section{Implications and Conclusions}

In what follows, I will summarise the main arguments put forward on the basis of the data and the theoretical implications which arise for early clause structure. First, with respect to the peripheral / non-peripheral distinction in clausal positions, focusing and interrogative structures, both involving verb-movement to a peripheral position $(\mathrm{F} / \mathrm{C})$ together with XP-movement to specFP (or specCP) have been compared with verbmovement to inflectional heads in the domain of the main clause. It was shown that the peripheral positions associated with Focus and Questions are acquired before Tense, Mood and Agreement positions, suggesting that 'truncation' and structurebuilding accounts for functional structure are not on the right track. An alternative suggestion formulated on the basis of LF-interpretability appears more promising (Tsimpli 1997, 2001, Tsimpli and Stavrakaki 1999). In particular, assuming that the Focus and Q features are LF-interpretable and appear in peripheral, scope positions they are predicted to be available to early grammars right from the start. Assuming that agreement features on the verb are not interpretable at LF (Chomsky 1995), the interpretability of Tense and Mood is the next question.

Chomsky 2001 suggests that Tense could be substantive and as such its interpretability at LF follows. He also makes the distinction between 'complete' and 'defective' $\mathrm{T}$ being related to the presence and absence of phi-features and $\mathrm{C}$. As far as child grammars are concerned, it is well-known that early verb forms do not exhibit 
Tense distinctions. Various analyses of this fact have been put forward suggesting the Aspect-before-Tense hypothesis (e.g. Antinucci and Miller 1976), maturation of Tense (Wexler 1992, 1994), delay in a pragmatic principle affecting tense interpretation (Hyams 1996), etc. As far as early Greek is concerned, it has been suggested that aspectual distinctions between perfective and imperfective forms appear earlier than [+/-past] tense distinctions (Katis 1984, Tsimpli 1992/96, Stephany 1986, 1997). In Tsimpli 1992/96 it is argued that Aspect is an argument of the verb and saturates the $<e>$ position of the verb (cf. Higginbotham 1985). I will maintain this analysis and suggest that the 'substantive' nature of temporal anchoring in adult grammars is instantiated by a Tense / Aspect relation possibly along the lines of Giorgi and Pianesi 1997, along with an aspectual distinction between situation types and viewpoint aspect in the sense of Smith 1991.

Giorgi and Pianesi 1997 argue for two tense projections, the lower one encoding the $\mathrm{R} / \mathrm{E}$ relation and the higher one the $\mathrm{S} / \mathrm{R}$ relation. If aspect is associated with the event position of the verb, the lower TP encodes a tense / aspect link in our terms. In the absence of tense in early grammars, $\mathrm{R}$ is missing and aspect is responsible for delimiting the contour of the event grammatically, i.e. by virtue of its structural representation inside the $\mathrm{VP}^{21}$. The interpretability of aspect at LF follows from its thematic status. The lack of tense projections in early clause structure also implies that there are two possible readings, either a modal (temporally, future) or a non-modal. In the non-modal interpretation, either the (unmarked) simultaneity of S,E is possible- which is also the apparently 'present tense' reading found frequently in early data- or a reading of 'pastness' in the sense of completion of the event as conveyed by the use of a perfective verb form (usually, a participle). In this case, event precedes speech time (E_S) and thus the past interpretation is derived. 
Regarding Mood, as already discussed in the preceding section, it is not equivalent to modality but grammaticalises features such as [+/-indicative], and [+/imperative] which happen to have distinct morphological realisations in Greek evidenced in terms of the subjunctive marker na and a distinct agreement paradigm respectively. Modality is expressed as an operator in the $\mathrm{C}$ position, i.e. the position where S (Speech Time) is also represented. Recall that the modal reading entails futurity but, crucially, not through tense marking. In the earliest stage, modal and nonmodal readings are structurally available, but Mood distinctions are not.

The distinction of features based on their interpretability also implies a different developmental pattern between focusing and interrogatives, on one hand, and dislocation / topicalisation patterns, on the other. Specifically, as argued in section 1, on the assumption that dislocation / topicalisation do not involve an operator-variable structure, the displaced constituent is not associated with a functional position hosting an interpretable feature and as such it is expected to be delayed compared to focusing. Notice that the two structures investigated here in early Greek, namely CLLD and CID, presuppose the acquisition of clitics which, have been argued to be clusters of uninterpretable features, i.e. case and (resumptive) agreement features lacking referentiality (cf. Cardinaletti and Starke 1994, Tsimpli 1999 for Greek). Thus, the fact that these two structures are indeed found later than focusing, can be explained on the basis of the delay in the development of clitics and not as a consequence of the absence of an interpretable feature associated with the structures themselves. However, in Alexia's and Elli's data, there seems to be a preference for CID over CLLD structures, which was argued above to be due to the verb-focusing effect closely associated with the former but not with the latter. Clearly, the evidence does not show a developmental difference between CID and CLLD in 
terms of consecutive stages of development (cf. Marinis 2002). Nevertheless, it is indicative of the priority of interpretable features in focusing (and, by consequence, in CID) and lack thereof in CLLD structures.

On the basis of the above discussion, the earliest clause structure in child Greek is schematically represented in the following tree-structure:

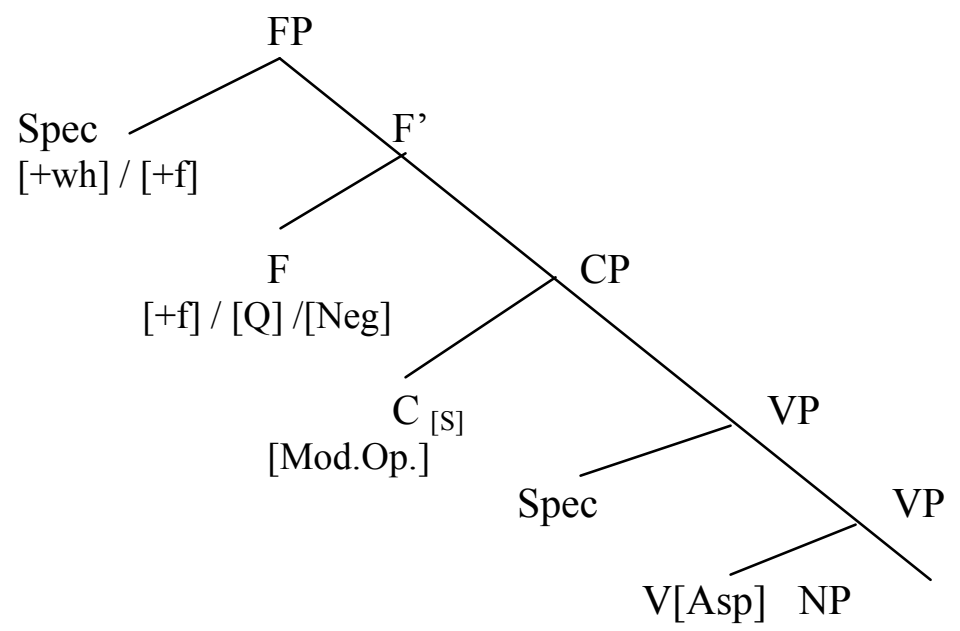

The inflectional domain of the clause develops in the second stage where Mood, Tense, Agreement and clitics develop. The almost simultaneous appearance of these inflectional categories suggests, once again, that neither structure-building nor truncation are accurate descriptions of language acquisition. Furthermore, notice that according to the structure in (21), the functional heads in the periphery are specified for LF-interpretable features only.

As discussed above in terms of the representation of modality, there are certain implications that this theory suggests with respect to the universality of early clause structure. For example, the prediction made for early modal sentences would be that a modal operator is available crosslinguistically in some peripheral scope position. However, this is not extended to all LF-interpretable features which happen 
to be represented in the early Greek clause in (21). Specifically, focusing, a grammaticalised feature in Greek, gives rise to adult-like focused structures even from the earliest stage. On the assumption that focus is grammaticalised in some languages and, furthermore, that, within this set of languages, its grammaticalisation is also parameterised (e.g. by movement in Greek and Hungarian, by movement plus a focus particle in Berber (Ouhalla 1994), it is predicted that syntactic focus structures in early data will be found in those languages where the input provides evidence for its grammaticalisation ${ }^{22}$. Furthermore, the different ways in which focus is grammaticalised would also play a role in the developmental pattern observed. Thus, it is possible that merge of a focus particle should be delayed compared to focusmovement of a consituent (verb or XP) for reasons that have to do with the functional versus lexical status of the element carrying the focus feature. Similarly, in English interrogatives, movement of the wh-phrase is expected to emerge earlier than I-to-C movement since the latter involves a functional element (also carrying uninterpretable (Infl) features) moving to the host of the Q feature. On the other hand, in languages like Greek and Italian, V-to-I-to-C is predicted to emerge earlier than the English I-to$\mathrm{C}$ structures since the difference is that between a lexical and a functional category.

Summarising, the theory proposed here is based on the earlier lexical / functional distinction which is, however, reformulated in view of the (functional) feature distinction on the basis of LF-interpretability. Interpretable features can be associated with PF-parameterisation, i.e. alternative ways of grammaticalising an LFinterpretable feature. Grammaticalised interpretable features are predicted to be available from the onset of language acquisition. Thus, interpretable features of the left-periphery, e.g. focus or wh-, are found earlier than formal features of inflectional categories. In addition, LF-interpretable features which are encoded on substantives 
are predicted to be acquired earlier than those encoded on functional elements (e.g. free or bound morphemes / particles - see Collins 1997 and fn. 8). PFparameterisation also involves uninterpretable features on functional heads (formal features), as in the case of (resumptive) agreement and case. In L1 acquisition, as soon as inflectional heads appear (around the age of $2 ; 0^{23}$ ), the lexical / functional and the interpretable / uninterpretable distinction do not have clear effects any more ${ }^{24}$ (see Tsimpli 2001 for the difference between normal and SLI children in terms of these distinctions). The clause structure develops with Mood, Tense and Agreement appearing in the clause structure together with their syntactic consequences, e.g. subject-verb agreement and the VSO order. In view of this pattern of development, the theory proposed here suggests that overt morphology does not drive syntax. Instead, a feature-based developmental pattern distinguishing between interpretable and uninterpretable features is argued to be more promising.

\section{Notes}

\footnotetext{
* As this volume is dedicated to a former teacher of mine, Professor Dimitra Theofanopoulou-Kontou, this is the right place to emphasize her invaluable contribution to Greek linguistics but also to my becoming a 'convert' to the discipline after my first degree. Greek linguistics has greatly benefited from Theofanopoulou-Kontou's research, teaching and guidance throughout the years. My 'thanks' are therefore added to the numerous other students and researchers who have had the chance to meet her and learn from her.

Many thanks go to the two anonymous reviewers for their insightful comments and suggestions. Parts of this paper have been presented at the 5th International Conference on Greek Linguistics in Paris as well as at the University of Cambridge and the University College London. Many thanks to the audiences there. Errors remain, of course, mine.

${ }^{1}$ In terms of discourse effects, topicalisation and CLLD are considered to be the same. I will assume that object DPs in Greek are CLLD-ed when specific, and topicalised when non-specific (cf. Anagnostopoulou 1994). The specificity difference does not always correlate with the presence vs absence of the definite D (e.g. Ena kafedhaki tha to epina efxaristos. Lit.: 'A cup of coffee, I would drink-it with pleasure').

${ }^{2}$ It seems that the development of the inflectional domain is not complete at the same time crosslinguistically. For example, in Greek and Spanish, the development of agreement appears earlier than in English. Presumably, parameterised options in the role of inflection and its morphological saliency determine the speed in which inflectional features are acquired.
} 
3 Topicalisation in English is analysed as involving operator-movement (of a null operator) and predication, both of which are LF-relevant constructs (Chomsky 1977, Culicover 1991). However, topicalisation and CLLD in Greek are, probably, the same discourse structure but differ only in the elements that participate in each. Thus, subjects can only be topicalised but not CLLD-ed in the absence of subject clitics, and bare indefinite objects may only be topicalised but not CLLD-ed in the absence of a determiner introducing the object (Theophanopoulou-Kontou 1986, Roussou \& Tsimpli 1994). I take it that such constraints distinguish between topicalisation and CLLD at PF but not at a discourse level.

${ }^{4}$ The question whether the clitic or the DP in clitic-doubling structures is the argument of the verb is controversial (cf. Anagnostopoulou 1999, Papangeli 2000, Philippaki-Warburton 1987, 1998, Schneider-Zioga 1993). For the purposes of this paper, it is not important to choose between the two analyses: the features relevant to the discussion on L1 acquisition are the focus feature associated with the verb and the features of the clitic (D, Agr and Case) which doubles the phrase.

${ }^{5}$ The structure is oversimplified. It could well be that the future particle tha is not merged in the same position with na (Agouraki 1991, Philippaki-Warburton 1998, Rivero 1994, Roussou 2000). A specification for a preverbal subject position is missing too. This could be in specTP or a dislocated position in the SVO order (see Alexiadou \& Anagnostopoulou 2000 for a recent review of alternative analyses).

${ }^{6}$ Data from the first stage of linguistic development, e.g. the two-word stage, can hardly provide empirical evidence for a fully-fledged clause structure of the type in (5) above: if a structural position is not used via either of the computational processes, i.e. merge or move, it is difficult to see how one can maintain availability of this position at the relevant stage, short of theoretical elegance, of course. In Hyams 1996, Harris \& Wexler 1996 a.o., strong continuity is defended with assumptions concerning 'underspecification' of functional features or some other operating constraint which does not appear in the adult grammar (see e.g. the unique feature-checking constraint, Wexler 1998).

${ }^{7}$ Radford 1990 suggests a maturation account for functional categories (see also Guilfoyle and Noonan 1988, Tsimpli 1992/96) whereas Radford 1996 proposes a weak-continuity approach with extra assumptions regarding lexical / morphological bootstrapping.

${ }^{8}$ Collins 1997 suggests that the + -interpretable distinction is based on a difference between inherent as opposed to relational features. Thus, phi-features on Nouns are inherent and therefore interpretable whereas phi-features on Verbs or Adjectives are relational and therefore uninterpretable. The contrast between interpretable and uninterpretable features in Chomsky's terms seems to cut across lexical and functional categories. However, categorial features, although inherently interpretable by minimalist assumptions, become uninterpretable at LF if the category that hosts them is functional (e.g. wh- in C is erased at LF but remains on the lexical category that enters in a checking relation with it - see Ndayirajige 1999 for discussion). As already mentioned above, I assume that the categorial features of functional or lexical heads, which are responsible for an operator-based dependency at LF, are available from the earliest stage. This is based on the idea that parameterisation involves uninterpretable features which, at the earliest stage, are not active in the grammatical derivation. I come back to this point in the final section.

${ }^{9}$ In Penner et al's 2000 account, the Focus Particle Phrase (FPP) belongs to the Middle Field. There is no a priori reason why grammaticalisation of focusing should always involve the projection of a leftperiphery FP, as is the case in Greek (see also Belletti 2001 for a 'low' FP in Italian). If interpretability of features characterises early clause structure and focus is +interpretable (being an individual operator), the implication is that evidence for its early emergence should be available in all languages where it is grammaticalised. Furthermore, this evidence should contrast with the (relatively) later emergence / acquisition of uninterpretable formal features (e.g. the expletive article introducing implicitly definite nouns) (see Penner \& Weissenborn 1996, Penner \& Hamann 1998).

${ }^{10}$ That focusing is an LF-interpretable feature is based on the analysis of focusing as an operatorvariable structure and, crucially, focus as a grammaticalised feature (as is the case in languages like Hungarian, for example, Brody 1990, Kiss 1995). In English and French, for example, focusing does not seem to be grammaticalised, i.e. it does not have effects on the derivation, in that identificational or contrastive focus interpretations are optionally associated with a variety of structures (clefts, topicalisation or in-situ). There are implications of this difference for the question of LF-universality but also for developmental issues: peripheral positions associated with LF-interpretable features in English, French etc. are not the same as those in Greek and therefore predictions regarding the development of these positions in English and French should be relevant to wh-movement in interrogatives but not focus movement. Languages which may offer some evidence regarding the 
development of peripheral positions in structures other than interrogatives are V2 languages but only in cases of non-subject clause-initial elements. However, in these languages it is not the focus feature which motivates V2; instead, the focus interpretation is possibly associated with object-initial structures at the post-LF level. Therefore, the comparison with Greek focus structures is not accurate in this case either.

${ }^{11}$ It is indeed possible for the verb to be focused in CLLD structures too. The point is that CLLD is not associated with verb-focusing in terms of the syntactic derivation (on Agouraki's 1993 assumptions) the way that clitic-doubling does.

${ }^{12}$ Interrogatives differ from focus structures in that morphological information is specified on the moved wh-phrase. In focus structures no morphological specification is associated with the moved constituent, only prosodic focus.

${ }^{13}$ I am grateful to Anna Roussou for letting me have access to Elli’s data.

${ }^{14}$ Utterances with imperative force are found even in earlier data. Notice, however, that in the early 'imperatives' the form used is the UFC (i.e. [-past, +perfective]) introduced by a vocalic place-holder (see below). In adult Greek, imperative force can be conveyed by the use of a matrix subjunctive e.g. na fijis ('you should leave') but also, unambiguously, by the use of morphologically-marked imperatives, e.g. Fije ('Leave'). In Alexia's data, morphological imperatives are attested at 2;2.

${ }^{15}$ In fact, all preverbal subjects in sentences including the UFC or modal particles have a focused subject interpretation.

${ }^{16}$ There are no instances of OSV structures in either child's data and therefore the assumption that V moves to F is also supported. However, given that most overt subjects in the child data are postverbal it is possible that the verb does not move to $\mathrm{F}$ when the object is focused, but remains in VP. The surface order would still be OVS in this case.

${ }^{17}$ This is the assumption Alexiadou and Anagnostopoulou 1998 make for adult Greek where they assume that the verb raises but the subject remains in specVP (cf. Roussou and Tsimpli 2002).

${ }^{18}$ Clitic-doubling and CLLD structures are also excluded although if the clitic is ignored, sentences including clitic-doubling could in principle be categorised as VSO or VOS. However, given that in clitic-doubling or CLLD structures the object is displaced to a peripheral position we cannot use these structures as evidence for the position of the subject.

${ }^{19}$ The SOV order is not found in either Elli's or Alexia's data. In the adult language it is possible to derive SOV by topicalising the subject and focusing the object. However, both in discourse and in syntactic terms, the SOV order is not comparable with the VSO: the latter can be discourse-neutral and 'canonical', according to most analyses of Greek word-order (see section 1) whereas the former is neither.

${ }^{20}$ Epistemic modality is not encoded in early data. Its development has been argued to correlate with the development of the Theory of Mind component for reasons that have to do with epistemic expressions involving a second-order representation (Papafragou 1997, Smith \& Tsimpli 1995, Tsimpli \& Smith 1998).

21 I take it that speech time (S) may be either pragmatically determined (the here-and-now) or structurally represented in a peripheral (C) position. Both possibilities are compatible with the present account, although theoretically I would opt for the latter if $\mathrm{C}$ is a position that encodes $\mathrm{S}$ universally.

${ }^{22}$ In verb-second languages, early data should also show focus structures with non-subject-initial constituents, where the displaced element is focused. Such examples are reported in various works on the acquisition of V2 (although the emphasis falls on the morphological status of the verb as [+/-finite] rather than the focused or unfocused status of the initial constituent). As suggested earlier, however, the motivation for XP-movement to a peripheral position in adult V2 clauses is not a focus feature (see also fn. 9). What is expected from early data from V2 languages, then, is sentences with non-subjects in initial position as focused elements, alongside with subjects in initial position (focused or not). In the first case, target-like movement to a peripheral position would be the appropriate structural description whereas in the latter, independent evidence is required to show that the same functional positions host the subject and the verb (see Poeppel \& Wexler 1993).

${ }^{23}$ In the second stage of development, then, inflectional heads are acquired. This is indeed strikingly early development and it is compatible (at some superficial level) with the 'very early parametersetting view' of Wexler 1996. However, since it is not Stage I, it is incompatible with Wexler's theory.

24 But categorial features do seem to determine the developmental sequence. For example, the complementiser oti (= 'that') in Greek develops later than resumptive clitics. If both elements are uninterpretable at LF, the developmental difference must be based on differences in categorial features. 
Other complementisers (e.g. the factive $p u$ ) develops earlier than 'that' and therefore the implication is that $\mathrm{C}$ elements develop gradually on the basis of their feature-composition. On the other hand, resumptive clitics, being Agr+Case elements develop as soon as these features are part of the child grammar. 


\section{References}

Agouraki, Y. 1990. "On the projection of maximal categories: the case of CP and FP in Modern Greek." UCL Working papers in Linguistics 2: 183-199.

Agouraki, Y. 1991. “A Modern Greek complementizer and its significance for Universal Grammar." UCL Working papers in Linguistics 3: 1-24.

Agouraki, Y. 1993. Spec-Head Licensing: The Case of Foci, Clitic-constructions and Polarity Items: A Case Study of Modern Greek. Ph.D. Dissertation, UCL.

Alexiadou, A. 1999. "On the properties of some Greek word-order patterns." In Studies in Greek Syntax, A. Alexiadou, G. Horrocks and M. Stavrou (eds), 45-65. Kluwer Academic Publishers.

Alexiadou, A. and Anagnostopoulou, E. 1998. "Parametrizing AGR: word order, verb movement and EPP-checking." Natural Language and Linguistic Theory 16: 142161.

Alexiadou, A. and Anagnostopoulou, E. 2000. "Greek syntax: A principles and parameters perspective.” Journal of Greek Linguistics 1: 171-222.

Alexopoulou, T. 1999. The Syntax of Discourse Functions in Greek: A NonConfigurational Approach. Ph.D. thesis, University of Edinburgh.

Anagnostopoulou, E. 1994. Clitic Dependencies in Modern Greek. Ph.D. Dissertation, University of Salzburg.

Anagnostopoulou, E. 2001. On Double Object Alternations and Clitics. Mouton de Gruyter.

Antinucci, F. and Miller, R. 1976. "How children talk about what happened." Journal of Child Language, 3: 167-189. 
Belletti, A. 2001. "Inversion as focalisation." In Subject Inversion in Romance and the Theory of Grammar, A. Hulk and J-Y Pollock (ed), 60-90. Oxford University Press.

Borer, H. 1984. Parametric Syntax: Case Studies in Semitic and Romance Languages. Dordrecht: Foris.

Brody, M. 1990. "Some remarks on the Focus Field in Hungarian." UCL Working papers in Linguistics 2: 201-225.

Chomsky, N. 1977. “On Wh-Movement.” In Formal Syntax, P. Culicover, T. Wasow and A. Akmajan (eds), 71-132. New York: Academic Press.

Chomsky, N. 1991. "Some Notes on the Economy of Derivation and Representation." In Principles and Parameters in Comparative Grammar, R. Freidin (ed.), 417454. Cambridge, Mass.: The MIT Press.

Chomsky, N. 1995. The Minimalist Program. Cambridge, Mass.: The MIT Press.

Chomsky, N. 2001. "Derivation by Phase." In Ken Hale: A Life in Language, M. Kenstowicz (ed.), 1-52. MIT Press.

Clahsen, H. (ed.) 1996. Generative Perspectives on Language Acquisition: Empirical Findings, Theoretical Considerations, Crosslinguistic Comparisons. Amsterdam and Philadelphia: John Benjamins.

Clahsen, H., Eisenbeiss, S and Penke, M. 1996. "Lexical Learning in Early Syntactic Development.” In Clahsen (ed.), 129-159.

Collins, C. 1997.Local Economy. MIT Press.

Culicover, P. 1991. “Topicalisation, Inversion and Complementisers in English.” In Going Romance and Beyond, D. Delfitto, M. Everaert, A. Evers and F. Stuurman (eds), 1-43. University of Utrecht. 
Drachman, G. and Klidi, S. 1993. "The Extended Minimal Structure Hypothesis." Studies in Greek Linguistics, 225-243.

Giorgi, A. and Pianesi, F. 1997. Tense and Aspect: From Semantics to Morphosyntax. Oxford University Press.

Guilfoyle, E. and Noonan, M. 1988. "Functional Categories and Language Acquisition." Paper presented at the 13th annual Boston University Conference on Language Development. Boston.

Haegeman, L. 1996. "Root infinitives, clitics and truncated structures." In Clahsen (ed.), 271-308.

Harris, T. and Wexler, K. 1996. "The Optional Infinitive Stage in Child English: Evidence from Negation." In Clahsen (ed.), 1-42.

Higginbotham, J. 1985. “On Semantics.” Linguistic Inquiry 16: 547-594.

Hoekstra, T. and Jordens, P. 1994. "From Adjunct to Head.” In Language Acquisition Studies in Generative Grammar, T. Hoekstra and B. Schwartz (eds), 119-149. Amsterdam and Philadelphia: J. Benjamins.

Hyams, N. 1994. "V2, Null Arguments and COMP Projections." In Language Acquisition Studies in Generative Grammar, T. Hoekstra and B. Schwartz (eds), 21-55. Amsterdam and Philadelphia: J. Benjamins.

Hyams, N. 1996. "The underspecification of functional categories in early grammar." In Clahsen (ed.), 91-128.

Hoekstra, T. and Hyams, N. 1998. “Aspects of root infinitives.” Lingua 106: 81-112.

Hyams, N. 2001. “Now you hear it, now you don't: The nature of optionality in child grammars." In Proceedings of the $25^{\text {th }}$ Annual Boston University Conference on Language Development, 34-58. Somerville MA: Cascadilla Press. 
Hyams, N. 2002. "Clausal Structure in Child Greek: A reply to Varlokosta, Vainikka and Rohrbacher and a reanalysis.” The Linguistic Review19:225-270.

Katis, D. 1984. The acquisition of the Modern Greek verb with special reference to the imperfective past and perfect classes. Ph.D. Dissertation. University of Reading.

Kiss, K. 1995. “Introduction.” In K. Kiss (ed.) Discourse Configurational Languages. Oxford University Press, 3-27.

Kiss, K. 1998. "Identificational focus versus information focus.” Language 74: 245273.

Marinis, T. 2000. "The acquisition of clitic objects in Modern Greek: Single Clitics, Clitic Doubling, Clitic Left Dislocation.” ZAS Working Papers 15.

Marinis, T. 2002. "Acquiring the Left Periphery of the Modern Greek DP.” Essex Research Reports in Linguistics 39: 1-30. University of Essex.

Ndayiragije, J. 1999. “Checking Economy.” Linguistic Inquiry 30, 3: 399-444.

Ouhalla, J. 1991. Functional Categories and Parametric Variation. London: Routledge.

Ouhalla, J. 1994. "Focus in Standard Arabic.” Linguistics in Potsdam 1: 65-92.

Palmer, F. 2001. Mood and Modality. 2nd Edition. Cambridge University Press.

Papafragou, A. 1997. "Modality in Language Development: A Reconsideration of the Evidence.” UCL Working papers in Linguistics 9. 77-106.

Papangeli, D. 2000. "Clitic Doubling in Modern Greek: A Head-Complement Relation." UCL Working papers in Linguistics 12. 473-498.

Penner, Z. and Hamann, C. 1998. "The emergence of discourse / syntax interface problems in impaired grammar." In Proceedings of the $22^{\text {nd }}$ Boston University Conference on Language Development, 626-639. Cascadilla Press, Somerville. 
Penner, Z., Tracy, R. and Weissenborn, J. 2000. “Triggering Object Scrambling.” In The Acquisition of Scrambling and Cliticization, S. Powers and C. Hamann (eds), 127-164. Kluwer Academic Publishers.

Penner, Z. and Weissenborn, J. 1996. "Strong Continuity, Parameter-Setting and the Trigger Hierarchy.” In Clahsen (ed.), 161-200.

Philippaki-Warburton, I. 1985. "Word Order in Modern Greek." Transactions of the Philological Society 2: 113-143.

Philippaki-Warburton, I. 1987. "The theory of empty categories and the pro-drop parameter in Modern Greek.” Journal of Linguistics 23: 289-318.

Philippaki-Warburton, I. 1994. "The Subjunctive Mood and the Syntactic Status of the Particle na in Modern Greek.” Folia Linguistica XXVIII/3-4: 297-328.

Philippaki-Warburton, I. 1998. "Functional Categories and Modern Greek Syntax." The Linguistic Review 15: 159-186.

Philippaki-Warburton, I. and Spyropoulos, V. 1999. “On the boundaries of Inflection and syntax: Greek pronominal clitics and particles." In The Yearbook of Morphology 1998, G. Booij and J. van Marle (eds), 45-72. Dordrecht : Kluwer.

Philippaki-Warburton, I., Varlokosta, S., Georgiafentis, M. and Kotzoglou, G. 2002. “On the status of clitics and their 'doubles' in Greek." In Reading Working Papers in Linguistics 6: 57-84.

Platzack, D. 1999. “Multiple Interfaces.” Ms, Lund University, Dept. of Scandinavian Linguistics.

Poeppel, D. and Wexler, K. 1993. "The Full Competence Hypothesis of Clause Structure in Early German.” Language 69: 1-33.

Radford, A. 1990. Syntactic Theory and the Acquisition of English Syntax: The Nature of Early Child Grammars of English. Oxford: Blackwell. 
Radford, A. 1996. "Towards a Structure-Building Model of Acquisition.” In Clahsen (ed.), 34-90.

Rivero, M. L. 1994. "Verb movement and the structure of IP in the languages of the Balkans.” Natural Language and Linguistic Theory 12: 63-120.

Rivero, M.L. and Terzi, A. 1995. "Imperatives, V-movement and logical mood." Journal of Linguistics, 33: 301-332.

Rizzi, L. 1994. "Early Null Subjects and Root Null Subjects." In Language Acquisition Studies in Generative Grammar, T. Hoekstra and B. Schwartz (eds), 151-176. Amsterdam and Philadelphia: John Benjamins.

Rizzi, L. 1997. "The Fine Structure of the Left Periphery.” In Elements of Grammar. Handbook in Generative Syntax, L. Haegeman (ed.), 281-337. Dordrecht: Kluwer.

Rouchota, V. 1994. The Semantics and Pragmatics of Subjunctive in Modern Greek: A Relevance-Theoretic Approach. Ph.D. Dissertation, UCL.

Roussou, A. 2000. "On the left periphery: Modal particles and complementizers." Journal of Greek Linguistics 1: 65-94.

Roussou, A. and Tsimpli, I. M. 1994. "On the Interaction of Case and Definiteness in Modern Greek." In Themes in Greek Linguistics, I. Philippaki-Warburton, K. Nicolaidis and M. Sifianou (eds), 69-76. Amsterdam and Philadelphia: John Benjamins.

Roussou, A. and Tsimpli, I. M. 2002. "Postverbal subjects and microparametric variation." Paper presented at the GLOW conference, Amsterdam.

Schneider-Zioga, P. 1993. The syntax of clitic doubling in Modern Greek. Ph.D. dissertation, USC, Los Angeles. 
Sifaki, E. 2001. "On the derivation of VOS in Greek." Paper presented at the $14^{\text {th }}$ International Conference on Theoretical and Applied Linguistics. Thessaloniki.

Smith, C. S. 1991. The Parameter of Aspect. Kluwer Academic Publishers.

Smith, N. V. and Tsimpli, I. M. 1995. The mind of a savant: Language learning and modularity. Oxford: Blackwell.

Stephany, U. 1986. "Modality.” In Language Acquisition, P. Fletcher and M. Garman (eds), 375-400. Cambridge University Press.

Stephany, U. 1997. "The acquisition of Greek." In The Crosslinguistic Study of Language Acquisition 4, D. Slobin (ed), 183-333. Hillsdale, NJ: Erlbaum.

Terzi, A. 1992. "PRO in Finite Clauses. A Study of the Inflectional Heads of the Balkan Languages.” Ph.D. dissertation, CUNY Graduate Centre.

Terzi, A. 1997. "PRO and null case in finite clauses." The Linguistic Review 14: 335 360.

Terzi, A. 1999. "Clitic Combinations, their Hosts and their Ordering." Natural Language and Linguistic Theory 17: 85-121.

Theophanopoulou-Kontou, D. 1986. “Empty categories in Modern Greek.” Glossologia 5:41-68.

Tsimpli, I. M. 1990. “The Clause Structure and Word Order in Modern Greek.” UCL Working papers in Linguistics 2: 226-258.

Tsimpli, I. M. 1992/1996. The Prefunctional Stage of First Language Acquisition: A crosslinguistic Study. Ph.D. Dissertation, UCL. New York and London: Garland.

Tsimpli, I. M. 1995. "Focusing in Modern Greek." In Discourse Configurational Languages, K. Kiss (ed.), 176-206. Oxford University Press.

Tsimpli, I. M. 1997. "Resumptive features and L2A: a minimalist account.” In Boston University Conference on Language Development 21: 639-655. 
Tsimpli, I. M. 1998. "Individual and Functional Reading for Focus, Wh- and Negative Operators: Evidence from Greek." In Themes in Greek Linguistics II, B. Joseph, G. Horrocks and I. Philippaki-Warburton (eds), 197-227. Amsterdam and Philadelphia: John Benjamins.

Tsimpli, I. M. 2001. "LF-Interpretability and Language Development: A Study of Verbal and Nominal Features in Greek Normally Developing and SLI Children.” Brain and Language 77: 432-448.

Tsimpli, I. M. and Smith, N. V. 1998. "Modules and Quasi-Modules: Language and Theory of Mind in a Polyglot Savant.” Learning and Individual Differences 10: 193-215.

Tsimpli, I. M. and Stavrakaki, S. 1999. "The effects of a morpho-syntactic deficit in the determiner system: the case of a Greek SLI child." Lingua 108: 31-85.

Varlokosta, S., Vainikka, A. and Rohrbacher, B. 1998. "Functional Projections. Markedness, and 'Root Infinitives' in early child Greek.” The Linguistic Review $15,187-207$.

Varlokosta, S. (this volume). "Eventivity, modality and temporal reference in early child Greek."

Wexler, K. 1992. Optional Infinitives, Head Movement, and the Economy of Derivations in Child Grammar. Occasional Paper 45, MIT Department of Brain Cognitive Science.

Wexler, K. 1994. "Optional Infinitives, Head Movement and the Economy of Derivations.” In Verb Movement, D. Lightfoot and N. Hornstein (eds), 305-350. Cambridge University Press. 
Wexler, K. 1996. "The development of inflection in a biologically-based theory of language acquisition.” In Toward a Genetics of Language, M. L. Rice (ed.), 113144. Mahwah, NJ: Lawrence Erlbaum. 